\title{
Gasto, eficiencia y objetivos en educación en El Salvador: una perspectiva internacional
}

\author{
Mark Gallagher* \\ AID-EI Salvador**
}

\section{Introducclón}

Para un pais que busca modernizarse, una fuerza de trabajo no educada constituirá una seria restricción. Se ha demostrado que la contribución de la educación al crecimiento económico puede ser sumamente grande. De hecho, "la mayoría de los economislas probablemente eslarán de acuerdo en que son los recursos humanos de una nación, no su capilal, ni sus recursos maleriales, lo que en última instancia delermina el carácler y rilmo de su desarrollo económico y social" (Todaro, 1977, p. 235). Las mejoras en la educación estimulan la produclividad y una fuerza de Irabajo mejor educada puede adaptarse mejor a las nuevas tecnologias y a las cambiantes condiciones del mercado. Es muy diticil introducir nuevas tecnologias cuando la fuerza de Irabajo no tiene la

- El autor agradece a Bill Harwood, Patsy Layne, Oscar Melhado y Clarence Zuvekas por su valiosa ayuda. Naturaimente, lodos los errores que quedan son del autor.

* Las opiniones expresadas son las del autor y no reflejan necesariamente los puntos de vista de la Agencia para el Desarrollo Internacional de los Estados Unidos. 
capacidad básica para entenderlas.'

Será a través de la educación básica que los más pobres de los pobres en El Salvador podrán salir de su pobreza. Sin un acceso adecuado a la educación primaria y secundaria, los pobres tendrán oportunidades de Irabajo limitadas, perspectivas limiladas de asimilar nuevas tecnologías, oportunidades limitadas de elevar su productividad y perspectivas limitadas de subir en la escala social. Toda sociedad tiene sus pobres. Sin embargo, loda sociedad que no da a los pobres la oportunidad de subir a una mejor posición social experimentará inconformidad y descontento social como resultado de tal Irustración. Este tipo de descontenio se acumulará hasla afeclar no sólo a los pobres, sino a lodos en el país. Un pais que acaba de salir de doce af́os de guerra civil debería estar muy preocupado por la consolidación de la paz y por asegurar que sus pobres tengan la oportunidad de aprender y prosperar.

Este trabajo trata sobre el financiamiento del sistema público de educación de El Salvador y su eliciencia, objetivos para mejorar la eficiencia y los costos de esas mejoras y de proveer una mayor y mejor educación. El trabajo se concentra en la educación primaria y secundaria.

\section{Tendenclas de la educación en El Salvador}

Ha habido muy poco progreso en la salisfacción de las necesidades educacionales de la población en edad escolar durante la última década y media. Por ejemplo, como se muestra en el cuadro 1, no se ha regisIrado ninguna mejora en la tasa bruta de escolaridad primaria, mientras que la lasa de escolaridad secundaria ha mejorado sólo levemente. Mientras tanto, la relación estudiante/maestro en las escuelas primarias en El Salvador tampoco ha mejorado duranle ese periodo. No es sorprendente, por 10 tanto, que la proporción de estudiantes que repiten grado haya permanecido casi constante en $8 \%$, mientras que la proporción de una cohorte que alcanza el cuarto grado no ha cambiado mucho $y$, en realidad, ha caido levemenle.

Por supuesto, pueden senalarse varias razones por la falta de mejora en el sistema educalivo de El Salvador. Entre éstas, la que más se escucha es la internupción en la provisión de servicios públicos en zonas conflictivas y la desviación de la atención a la provisión de servicios públicos hacia la lucha contra el movimiento guerrillero.

1. Para cálculos de la contribución de distintos factores al crecimiento económico, véase Denison (1962). Para una discusión sobre tecnologla, educación y desarrollo, véase Solow (1957). Gallagher (1991) muestra también el impacto del gasto en educación sobre el crecimiento económico para un grupo de palses alricanos. 


\section{Cuadro 1}

El Salvador: Indlcadores soclales de desarrollo

\begin{tabular}{|c|c|c|c|c|c|c|c|c|c|c|c|c|c|c|}
\hline & 1976 & 1977 & 1978 & 1979 & 1980 & 1991 & 1982 & 1983 & 1994 & 1985 & 1986 & 1987 & 1988 & 1989 \\
\hline $\begin{array}{l}\text { Pobleción 0-14 años, } \\
\% \text { del tolal }\end{array}$ & 46 & 46 & 46 & 46 & 46 & 46 & 46 & 46 & 46 & 46 & 46 & 46 & 45 & 45 \\
\hline $\begin{array}{l}\text { Gasto en educación } \\
\% \text { del PIB }\end{array}$ & & & & & 4 & & & & & & & & & \\
\hline $\begin{array}{l}\text { Tasa bruta de escolaridad, } \\
\text { primaria, total }\end{array}$ & & 76 & 78 & 79 & 75 & & & 73 & 74 & & $\cdot$ & 79 & & \\
\hline $\begin{array}{l}\text { Tesa bruta de escolaridad, } \\
\text { primaria, femenina }\end{array}$ & & 76 & 77 & 79 & 75 & & & 73 & 75 & & & 81 & & \\
\hline $\begin{array}{l}\text { Tasa bruta de escolaridad, } \\
\text { secundarie, total }\end{array}$ & 21 & 23 & 25 & 26 & 24 & & 234 & 26 & 27 & & & 29 & & \\
\hline $\begin{array}{l}\text { Tasa bruta de escolaridad, } \\
\text { secundaria, lemen. }\end{array}$ & 19 & 21 & 23 & 24 & 23 & & 23 & 27 & 28 & & & 30 & & \\
\hline $\begin{array}{l}\text { Razón estud./maestro, } \\
\text { primeria }\end{array}$ & 46 & 53 & & & 48 & 41 & 45 & 48 & 42 & & & 45 & & \\
\hline $\begin{array}{l}\text { Razón estud./maestro, } \\
\text { secundaria }\end{array}$ & & & & & 13 & 12 & & & & & & & & \\
\hline $\begin{array}{l}\text { Estudantes que alcanzan } \\
40 . \text { grado, \% de cohorte }\end{array}$ & 57 & 59 & 58 & 59 & 54 & & & 54 & 66 & & & & & \\
\hline $\begin{array}{l}\text { Tasa de repetición, } \\
\text { primaria }\end{array}$ & B & $B$ & 8 & & & 9 & $B$ & 8 & $B$ & & & 8 & & \\
\hline $\begin{array}{l}\text { Tasa de analfabetismo. } \\
\text { total (Poblac.) } 15 \text { años) }\end{array}$ & & & & & 33 & & & & & 28 & & & & \\
\hline $\begin{array}{l}\text { Tasa de anallabetismo, fem. } \\
\text { (Poblac.) } 15 \text { años) }\end{array}$ & & & & & & & & & & 31 & & & & \\
\hline
\end{tabular}

Fuente: Banco Mundial, Social Indicators of Development, diskeltes STARS, 1991. 
No es sorprendente que el país no haya progresado en la provisión de educación básica para su población. Cuando se considera que la mayor parte del gaslo en educación en el país se canaliza a través del gobierno central, dadas las tendencias en el gasto en educación del gobierno central, es sorprendente que todo el sistema de educación pública no haya colapsado lotalmente. Por ejemplo, aunque el gasto en educación del gobierno central era $3.6 \%$ del producto inlerno bruto (PIB) en 1980, en 1991, después de un declive constante, como lo muestra el gráfico 1 , el gaslo en educación ha caído a sólo $1.7 \%$ del PIB aproximadamente. En términos del gasto en educación por estudiante, el gasto real ha caído a lo largo del periodo. Casi todo el gaslo en educación se concentra en los niveles primario y secundario. En realidad, la proporción del gasto en educación destinada a los niveles primario y secundario se incrementó de menos del $80 \%$ del total a finales de los setenta a aproximadamente $85 \%$ a finales de los ochenta. La educación superior es linanciada casi en su totalidad con fondos privados, siendo la Universidad de El Salvador la única universidad estatal entre las 36 universidades del pais. Esta leve mejora en la proporción del gasto en educación destinado a la educación básica, aunque real, no es muy importante y no revierte en absoluto las tendencias globales del volumen decreciente de recursos públicos disponibles para la educación básica en El Salvador. Las tendencias del gasto público en educación para el período 1976-9 se presentan en el cuadro 2.

\section{Gráfico 1}

\section{Gasto gubernamental en educación como porcentaje del PIB}

Porcentje del PIB

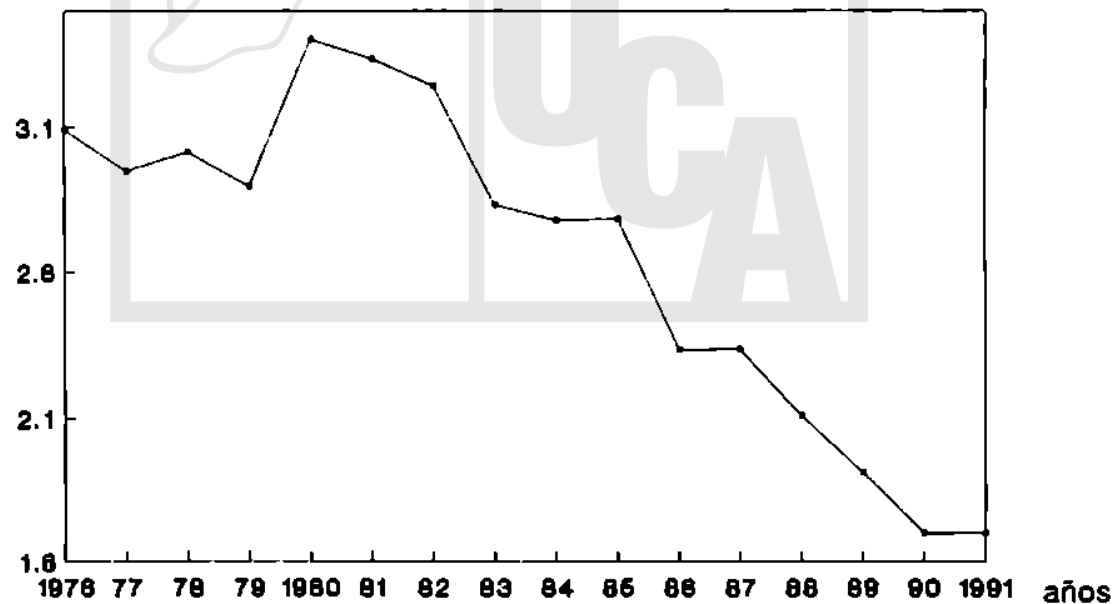




\section{Cuadro 2}

El Salvador: Gasto en educaclón públlca (colones de 1989)

\begin{tabular}{|c|c|c|c|c|c|c|c|c|c|c|c|c|c|c|c|c|}
\hline & 1976 & 1977 & 1978 & 1979 & 1980 & 1981 & 1982 & 1983 & 1984 & 1985 & 1986 & 1987 & 1988 & 1989 & 1990 & 1991 \\
\hline $\begin{array}{l}\text { GASTO REAL } \\
\text { EDUCACION, } \\
\text { TOTAL" }\end{array}$ & 677 & 684 & 746 & 705 & 758 & 679 & 660 & 566 & 590 & 653 & 619 & 659 & 658 & 616 & 611 & 634 \\
\hline $\begin{array}{l}\text { Gasto } \\
\text { corriento }\end{array}$ & & 633 & 704 & 674 & 714 & 663 & 638 & 535 & 561 & 606 & 571 & 575 & 589 & 585 & & 585 \\
\hline $\begin{array}{l}\text { Gasto de } \\
\text { capitale" }\end{array}$ & & 51 & 41 & 31 & 44 & 17 & 22 & 31 & 29 & 47 & 49 & 83 & 69 & 31 & 611 & 634 \\
\hline $\begin{array}{l}\text { Gasto en } \\
\text { prim. y sec. }\end{array}$ & 507 & 497 & 543 & 530 & 610 & 564 & 594 & 489 & 525 & 553 & 504 & 516 & 504 & 501 & & \\
\hline $\begin{array}{l}\text { Población } \\
\text { en prim. y } \\
\text { sec. (mill.) }\end{array}$ & 0.94 & 0.98 & 1.04 & 1.08 & 1.04 & 1.05 & 1.06 & 1.07 & 1.10 & 1.14 & 1.18 & 1.23 & 1.22 & 1.25 & 1.25 & 1.31 \\
\hline $\begin{array}{l}\text { Gasto real } \\
\text { por estud. } \\
\text { prim. y sec. }\end{array}$ & 538 & 506 & 520 & 489 & 586 & 536 & 558 & 456 & 475 & 485 & 426 & 421 & 413 & 401 & & \\
\hline $\begin{array}{l}\text { Gasio nominal } \\
\text { por estud., } \\
\text { prim. y sec. }\end{array}$ & 140 & 156 & 162 & 173 & 234 & 227 & 246 & 232 & 261 & 296 & 317 & 345 & 361 & 401 & & \\
\hline
\end{tabular}

Fuentes: Government Finance Statislics (FMI), Gobierno de El Salvador y AID-EI Salvador.

- Los dalos de gasto (a precios de 1989) se deflactaron usando el deflactor del gasto de consumo final del gobierno.

*. Incluye los gastos de SETEFE 
Estas tendencias indican con bastante claridad la falta de progreso en educación en El Salvador desde finales de los setenla. La falla de datos no permile un análisis sobre las tendencias sociales y en la educación desde 1987.

La próxima sección ołrece varias comparaciones internacionales. Estas comparaciones ayudarán a establecer la disponibilidad relativa de recursos educaciones en El Salvador, qué tan bien han sido usado esos recursos y la educacionales que como resultado se ofrece en EI Salvador. Eslas comparaciones no pueden delallar las fallas y fortalezas básicas en el sistema educativo salvadoreho, pero pueden ser útiles para sefialar grandes diferencias entre El Salvador y otros paises de un nivel similar de desarrollo, y pueden ayudar a determinar objetivos para mejorar el sislema educalivo salvadorefio. Con el tin de la guerra en El Salvador y la llegada de la paz y de esperanzas para una economia dinámica, el establecimiento de objetivos para mejorar la educación básica y el costeo de esas mejoras es necesario, tanto para el aseguramiento de la paz como para el aseguramiento de recursos humanos adecuados para la esperada reanudación del crecimiento económico del país.

\section{Comparaciones Internacionales}

Desde una perspectiva internacional, el sistema de educación pública de El Salvador está subfinanciado y es ineficiente. Por ejemplo, si hacemos una regresión entre el gasto público por esludiante en educación y el PIB percápila para un grupo de paises en desarrollo, encontramos que el gasto esperado por estudiante en El Salvador es de aproximadamenle $\$ 130$, mientras que la cilra real para 1991 lue de sólo \$65. También, dado un nivel de gasto de $\$ 65$ por estudiante, la relación estudiante/maestro que cabria esperar en las escuelas primarias a partir de comparaciones internacionales sería de aproximadamente 39; sin embargo, la relación estudiante/maestro realmente observada ha sido de 45 aproximadamenle. Por lo tanto, el gaslo de $\$ 65$ por estudiante compró en realidad menos profesores por estudiante que lo que cabria esperar de la comparación internacional. $Y$ dada la relación estudiante/maeslro de $\mathbf{4 5}$ en El Salvador, de las comparaciones internacionales se habria esperado que las escuelas primarias del país rindieran un tasa de progresión de primero a cuarto grado de $72 \%$; sin embargo, la tasa de progresión realmente obsenvada fue de sólo $58 \%{ }^{2}$ Eslas comparaciones se explican abajo.

2 La tasa de progresión hace referencia al número de estudiantes que terminan un grado (en este caso cuarto grado) como porcentaje del número de estudiantes en la cohorte original que entraron cuatro años antes al sistema de escuela primaria. 
Demanda de gasto gubernamental en educación. Todo un cuerpo de literatura ha crecido a partir del concepto de demanda de servicios provistos por el sector público. ${ }^{3}$ Entre los servicios demandados del gobierno por el público en la mayoría de países, especialmente entre los paises menos desarrollados (PMD), se encuentra la educación básica y algunas veces la educación superior. De hecho, podemos postular que entre más rico es un pais, al menos entre los PMD, más demandará de su goblerno para gastar en educación básica. Hemos estimado la demanda de educación como relación estadistica de corle transversal en una muestra de PMD.` El gráfico 2 muestra la relación generalmenle positiva entre el nivel de ingreso percápila y el gasto por estudiante en una muestra de PMD. La línea en este grálico representa la línea de tendencla generada mediante el uso del método de regresión. Como puede verse claramente, El Salvador cae por debajo de la linea de tendencia. Los resultados de esta regresión se presentan en el cuadro 3.

\section{Gráflco 2 \\ Educación pública en PMD* \\ (US dólares)}

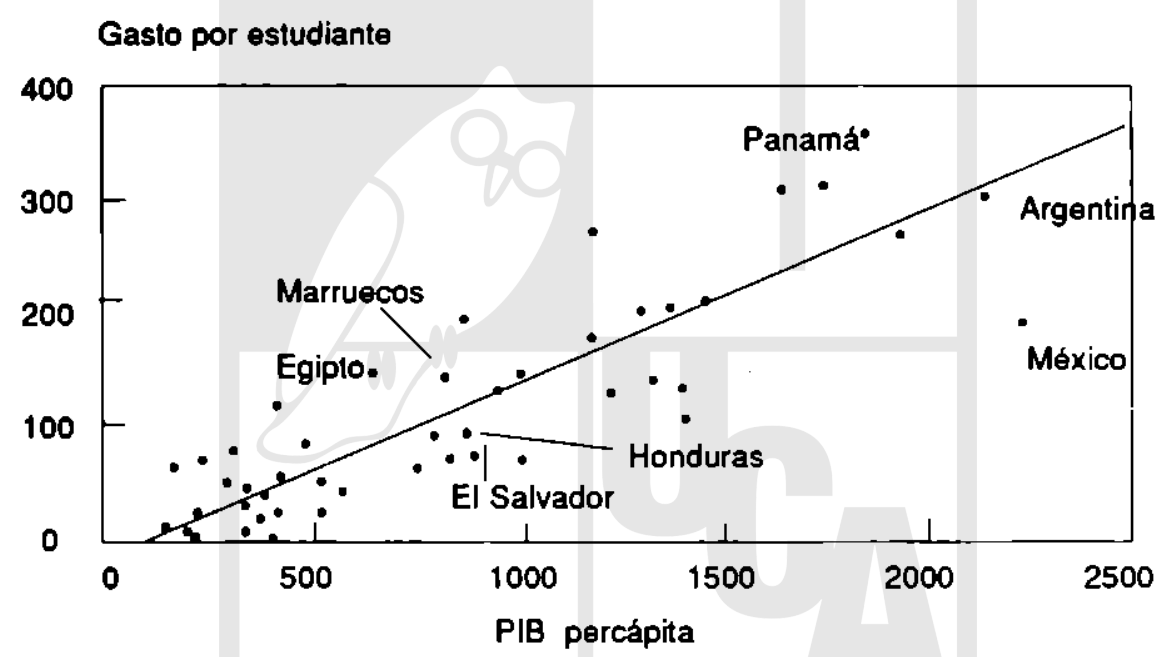

- Los paises bajo la linea gastan menos de lo esperado.

3 Esta literatura comenzó, quizá, con la famosa Ley de Wagner, que se encuentra en Wagner (1890) y que en años más recientes ha continuado siendo investigada en Ram (1986 y 1987).

4 La base de datos básica usada en el análisis comparativo internacional se encuentra en el anexo A1. 


\section{Cuadro 3}

Estimaclón de la demanda de gasto en educación pública

\begin{tabular}{|c|c|c|c|c|}
\hline $\begin{array}{l}\text { Gasto por estudiante } \\
\text { en educación pública }\end{array}$ & Constante & PIB percápita & $\mathrm{R}^{2}$ & g.l. \\
\hline & -7.68 & $\begin{array}{c}0.149 \\
(12.05)\end{array}$ & 0.76 & 45 \\
\hline
\end{tabular}

Notas: 1) EI PIB percápita y el gasto en educación pública se obtuvieron del Banco Mundial, Social Indicators of Development, diskettes STARS, 1992.

2) La muestra comprende 47 PMD. La base de datos se encuentra en el anexo 1.

3) El dalo en paréntesis corresponde al estadístico t, e indica un nivel de conlianza superior al $99 \%$.

4) g.l.: grados de libertad.

Los datos se ajuslan bastante bien a la regresión. El $\mathrm{A}^{2}$ indica que la regresión explica aproximadamente el $75 \%$ de las variaciones en la demanda de gasto en educación pública en la muestra de paises, mientras que el estadístico $t$ indica un nivel de confianza superior al $99 \%$ en la exactitud del coeficiente estimado. Naturalmente, eslas gruesas relaciones esladisticas no pueden explicar completamente la demanda ni la olerta resultante de gasto en educación en ningún pais en particular; sin embargo, si ofrecen una perspecliva internacional referente al problema de la adecuación del gasto en educación dados los recursos de que dispone un pais.

De acuerdo con los resultados de regresión presentados en el cuadro 3 , se esperaba que El Salvador gaslara aproximadamente $\$ 130$ por estudiante, pero en afios recienles sólo gaslo $\$ 65$, la mitad del valor esperado. En cambio, el pais vecino Honduras, que tenia un PIB percápita aproximadamente $10 \%$ inferior al de El Salvador, gastó $27 \%$ más por estudiante. EI PIB percápita de Tailandia es muy similar al de EI Salvador; sin embargo, Tailandia gastó casi el doble por esludiante (\$122).

Gasto y maestros. Aparte de cuánto gasta un pais en educación, es imporlante examinar lo que un pais compra en recursos para la producción en educación. Una simple, pero úlil, comparación entre paises es estimar la relación entre gasto por estudiante y la razón estudiante/ maestro en educación primaria. Podría esperarse que entre mayor es el gaslo por esludianle, menor será la razón estudiante/maestro. Hemos estimado esla relación, cuyos resullados se presentan en el cuadro 4. 
Cuadro 4

Estimación de la relación entre gasto por estudlante y la razón estudlante/profesor en primarla

\begin{tabular}{|c|c|c|c|c|}
\hline Razón estudiante/maestro & Constante & PIB percápita & $\mathrm{R}^{\mathbf{2}}$ & g.I. \\
\hline & 42.616 & $\begin{array}{c}-0.058 \\
(3.91)\end{array}$ & 0.39 & 39 \\
\hline
\end{tabular}

Notas: 1) Todos los dalos son de Banco Mundial, Social Indicators of Development (versión disketles STARS, 1992), excepto los gastos por estudiante, que se estimaron según se indica en las nolas al anexo 1.

2) El dato en paréntesis es el estadístico t, que indica un nivel de significancia superior al $99 \%$.

3) g.l.: grados de liberlad.

Esta regresión indica una fuerte relación inversa entre el gasto por esludiante y la razón esludiante/maestro, como se evidencia por la alta significancia del estadístico $\mathrm{t}$. Sin embargo, el $\mathrm{A}^{2}$ indica que sólo el $30 \%$ aproximadamente de la varianza en las razones estudiante/maestro entre los paises puede ser explicada mediante esta regresión. Por lo tanto, es claro que la lorma en que los recursos financieros se usan para comprar insumos de ensefianza no es automática y varia grandemente de pais a pais.

La razón estudianle/maestro esperada de esta ecuación para El Salvador es de 39, mientras que la razón observada realmente a mediados de los ochenla fue de 45 . Esla diferencia no es grande, sugiriendo que la cifra esperada quizá podría ser alcanzada mediante la reasignación de los recursos existentes, sin necesariamente cambiar el nivel de gasto en educación.

La razón estudiante/prolesor es sólo un indicador del uso de recursos financieros para la compra de insumos para la educación. Entre olros insumos se encuentran: escritorios, sillas, papel, lápices, edificios, mantenimiento de infraestruclura lísica, capacilación de profesores, equipo audiovisual, programas de radio y televisión, elc. Desaforlunadamente, no se dispone de ninguno de eslos insumos para un número suficiente de países como para hacer comparaciones internacionales de utilidad.

Recursos y eficiencia productiva. La provisión de maestros, como se mencionó arriba, es un insumo importante para la educación de la población. Varios indicadores de producción pueden reflejar qué tan bien están educando a sus estudiantes esos maestros. Un indicador útil de producción educacional y de eficiencia en la producción de población con 
educación es la "lasa de progresión hasta cuarto grado". Este indicador se calcula como el número de nifios que llegaron a cuarto grado como porcentaje de su cohorte que entró a primer grado. Hay una fuerte relación inversa entre el número de estudiantes por maestro en las escuelas primarias de un pais y la tasa de progresión de estudiantes hasta cuarto grado. Se espera que entre mayor es la razón estudiante/maestro, menor será la tasa de progresión hasta cuarto grado. Usando la lasa de progresión hasla cuarto grado como la variable dependienle y la razón esludiante/maestro en las escuelas primarias como la variable explicativa (o independiente), se probó está relación usando análisis de regresión. Los resultados se presentan en el cuadro 5.

\section{Cuadro 5}

Estimación de la relación entre la razón estudlante/maestro en primarla y la tasa de progresión hasta cuarto grado

\begin{tabular}{|l|c|c|c|c|}
\hline $\begin{array}{l}\text { Tasa de progresión } \\
\text { hasta cuarlo grado }\end{array}$ & Constante & PIB percápita & $\mathrm{R}^{2}$ & $\mathrm{~g} . \mathrm{l.}$ \\
\hline & 101.97 & $\begin{array}{c}-0.723 \\
(3.64)\end{array}$ & 0.26 & 38 \\
\hline
\end{tabular}

Notas: 1) Todos los datos se tomaron de Banco Mundial, Social Indicators of Development (diskeltes STARS, 1992), excepto el gasto por esludiante que se estimó según se indica en las nolas al cuadro 2.

2) El dato en paréntesis es el estadistico 1 , que indica un nivel de significancia superior al $99 \%$.

3) g.l.: grados de liberlad.

Esta regresión establece claramente la relación estadistica inversa entre la razón estudianle/maestro y la tasa de progresión de una cohorte entrante hasta cuarto grado. La fuerza de esta relación la muestra el estadístico t, el cual indica un $99 \%$ de contianza estadística en cuanto a que el coeficiente estimado es significalivamente menor que cero. Al mismo tiempo, sin embargo, como con en la relación entre gasto y la razón estudiante/maestro, sólo el $26 \%$ en la varianza en la lasa de progresión entre los paises es explicada por esta limilada ecuación. Por to tanto, otros lactores, no considerados en esta ecuación, juegan un rol importante en la determinación de la lasa de progresión. No obstanle, la razón estudiante/maestro observada en EI Salvador conduce a esperar una tasa de progresión hasta cuarlo grado de $72 \%$; sin embargo, sólo $58 \%$ de los nuevos entrantes a primer grado en El Salvador puede esperarse que continúen sin tropiezos hasla el cuarto grado. 
Resumen de hallazgos de las comparaciones internacionales. Este grueso análisis identifica tres aparentes deficiencias en el sislema educalivo salvadoreño: 1) El Salvador gasla aparenlemente mucho menos por estudiante de lo que cabria esperar dado el ingreso percápita del país; 2) dado el nivel de gasto por estudiante en El Salvador, la razón estudiante/maes/ro es un tanto alta; y 3 ) dado el nivel de recursos (financieros y en maestros), el sistema educativo salvadorefo podría desempenarse mejor educando a sus esludiantes y haciéndoles avanzar en niveles de educación, especialmente hasta el cuarto grado.

\section{La necesidad de mejorar la eflclencla}

Los datos disponibles del último censo de educación, realizado para el año 1987, han permitido al Ministerio de Educación hacer algunas proyecciones base de nuevos entrantes al flujo de educación primaria, el número lotal de anos de educación provislos a los estudiantes, el número de esludiantes promovidos, el número de esludiantes desertados, deserción entre grados, el número de estudiantes que repiten, elc. Estas proyecciones incluyen tasas constantes de repetición y deserción, con los niveles y lasas de promoción resullantes de cada grado. Las tasas no son indicadores de un alto nivel de eficiencia en lérminos de la cantidad de anos escolares que se requieren para que un estudianle complete sex10 grado. Las tasas de repetición van de $16 \%$ en primer grado a $2 \%$ en sexto grado. Al mismo liempo, las lasas de deserción de clases van de $20 \%$ para los estudiantes de primer grado a $11 \%$ para los de sexto grado. Estas lasas de ineficiencia generan una tasa de progresión hasta sexto grado de sólo $41 \%$.

Los esfuerzos por mejorar la eficiencia del sistema educalivo y de ensenanza quizá podrian ayudar a reducir las tasas de deserción y repetición significativamente. El mejoramiento de la calidad de la educación provista por los maestros por distintos medios, incluyendo la reducción de la razón estudiante/maestro (es decir, el tamano de la clase) podría ayudar a reducir la repetición de grados. ${ }^{5}$ Otras mejoras en la educación, como el incremento de la disponibilidad de texlos, papel y material de apoyo para la ensenanza en las aulas, asi como el mejoramiento de tacilidades podrían también ayudar a mejorar la educación mediante el mejoramiento de la atmóstera en que los nifios aprenden. Un mayor acceso a bibliotecas y otros materiales podría también ayudar

5. El anexo 2 presenta el escenario base del Ministerio de Educación basado en el censo de 1987. Los anexos 3 y 4 presentan las mismas variables con nuevas melas de tasas de repetición y deserción. 
a reducir la repetición de grados y hacer la escuela más atractiva para los estudiantes, reduciendo asi su disposición a deserlar. Los esfuerzos por mejorar las habilidades de ensefianza de los maestros podrian, naturalmente, reducir lambién la repetición y deserción.

Otros cambios en la forma en que la educación se provee en El Salvador también ayudarian a mejorar la eficiencia del sistema educativo y hacer la instrucción una allernaliva más atractiva para los nifos de las familias pobres. ${ }^{6}$ Por ejemplo, una supervisión más cercana de los maestros, ya sea por parte de los padres de familia o por parte de supervisores del Minislerio de Educación aseguraria que los maestros se hagan presentes en las escuelas y lleguen a tiempo. Las llegadas tardías y el ausentismo de los maestros ha constiluido un serio problema en varias escuelas. Además, algunos maestros son presa de la mala interpretación de que hacer que los estudiantes repitan un afio escolar es una indicación del rigor exigido por el prolesor y por tanto de su capacidad.

El tiempo real de ensenanza en muchas escuelas es insuliciente. Aunque el dia escolar oficial en El Salvador consla de cuatro horas, varias escuelas tienen un dia escolar abreviado de sólo tres horas, debido a la aglomeración y los tumos múltiples en las escuelas. Mientras tanto, la necesidad de recolectar lextos y materiales de los salones de abastecimiento central en las escuelas y ordenar de nuevo los escrilorios usados durante una sesión previa para acomodar las necesidades de la sesión siguiente, unido al carácter general de las llegadas tardias, han resultado en que el tiempo real de ensehanza haya sido reducido a sólo dos horas de clase por dia.

La enseñanza en las aulas necesita extenderse; las escuelas necesitan administrar mejor los materiales y texlos, y el dia escolar abreviado deberia ser eliminado.

Las escuelas que tienen varios turnos lienen también varias adminisIraciones. Cabria esperar, aunque no con loda certeza, que si cada escuela tuviera sólo una administración esto reduciria los coslos, elevaria la responsabilidad y aseguraria una mejor atención y manejo del personal y las facilidades, todo a menores costos. En cualquier caso, si la adminisIración múlliple continúa, debería imponerse una coordinación y los padres de familia y el Ministerio de Educación deberian exigir responsabilidad.

6. Los comentarios de este párrafo se basan en visitas a escuelas, conversa. ciones con maestros, estudiantes, padres de familia y supervisores del Ministerio de Educación y expertos internacionales que tienen que ver con el sistema educativo salvadoreño. 


\section{Establecimlento de objetivos}

Los cambios recomendados son meramente sugestivos y aqui no se evalúan sus costos y utilidad. Sin embargo, dada la comparación internacional hecha en la sección 2, pudiera ser concebible lograr reducciones en las tasas de repetición y deserción en una escala de aproximadamente $20 \%$, es decir, pudiera ser un objetivo razonable esperar reducir las lasas de repetición y deserción en $20 \%$, con relación a su nivel aclual, para el año 2000. Al mismo tiempo, el duplicar la cantidad gaslada por estudiante sólo llevaría a El Salvador al nivel de gasto en educación que cabría esperar se logre sobre la base de los resullados de regresión del cuadro 3.

El grálico 3 ofrece un escenario base elaborado por el Ministerio de Educación sobre el número de ańos escolares en adiestramiento que debe proveerse a nivel primario, empezando en 1993. Llevando a cabo las mejoras sefhaladas arriba, es decir, reduciendo la repelición y deserción, puede poslularse un escenario más eficiente. Con la reducción de las deserciones, el sistema educativo lendria que proveer educación para un número creciente de esludiantes cada afio, aunque esto supone que el número de nuevos entrantes al llujo de educación primaria sigue siendo consistente con las proyecciones base. El cuadro 6 resume los objetivos de eficiencia para las escuelas públicas primarias.

\section{Grátlco 3}

\section{Cantidad de instrucción por año en El Salvador*}

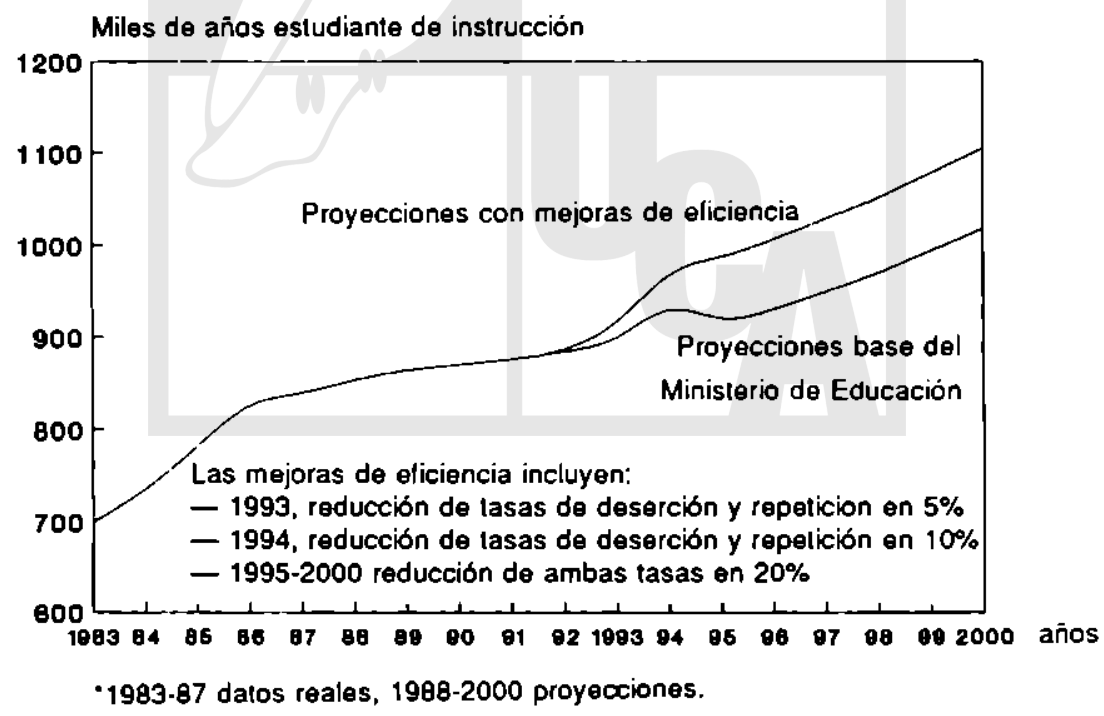


Cuadro 6

Eflclencla del sistema de educaclón primaria en El Salvador

\begin{tabular}{|c|c|c|c|}
\hline Grado & Indicador & Base & $\begin{array}{c}\text { Objetivo para el afno } \\
2000\end{array}$ \\
\hline 1 & $\begin{array}{l}\text { Promoción } \\
\text { Repetición } \\
\text { Deserción }\end{array}$ & $\begin{array}{l}64 \\
16 \\
20\end{array}$ & $\begin{array}{l}71 \\
13 \\
16\end{array}$ \\
\hline 2 & $\begin{array}{l}\text { Promoción } \\
\text { Repelición } \\
\text { Deserción }\end{array}$ & $\begin{array}{r}80 \\
8 \\
12 \\
\end{array}$ & $\begin{array}{r}83 \\
7 \\
10 \\
\end{array}$ \\
\hline 3 & $\begin{array}{l}\text { Promoción } \\
\text { Repetición } \\
\text { Deserción }\end{array}$ & $\begin{array}{l}83 \\
16 \\
10\end{array}$ & $\begin{array}{r}87 \\
5 \\
8\end{array}$ \\
\hline 4 & $\begin{array}{l}\text { Promoción } \\
\text { Repetición } \\
\text { Deserción }\end{array}$ & $\begin{array}{r}83 \\
4 \\
13\end{array}$ & $\begin{array}{r}86 \\
3 \\
10\end{array}$ \\
\hline 5 & $\begin{array}{l}\text { Promoción } \\
\text { Repetición } \\
\text { Deserción }\end{array}$ & $\begin{array}{r}88 \\
3 \\
10 \\
\end{array}$ & $\begin{array}{r}90 \\
2 \\
8\end{array}$ \\
\hline 6 & $\begin{array}{l}\text { Promoción } \\
\text { Repetición } \\
\text { Deserción }\end{array}$ & $\begin{array}{r}87 \\
2 \\
11 \\
\end{array}$ & $\begin{array}{r}90 \\
2 \\
9 \\
\end{array}$ \\
\hline Dara 199 & $\begin{array}{l}\text { Ingreso planeado } \\
2 \text { y } 2000\end{array}$ & $\begin{array}{l}208,000 \text { nuevos en- } \\
\text { entrantes a primaria }\end{array}$ & $\begin{array}{l}247,000 \text { nuevos en- } \\
\text { trantes a primaria }\end{array}$ \\
\hline & $\begin{array}{l}\text { Promoción de } \\
60 \text {. grado para } \\
\text { el ano } 2000\end{array}$ & 81,000 & 112,000 \\
\hline & $\begin{array}{l}\text { Total de anos } \\
\text { de insirucción }\end{array}$ & 884,000 & $1,104,000$ \\
\hline & $\begin{array}{l}\text { Tasa de } \\
\text { progresión } \\
\text { hasla } 60 . \text { grado }\end{array}$ & $41 \%$ & $51 \%$ \\
\hline
\end{tabular}

Fuente: Los datos base provienen del Ministerio de Educación. Las mejoras de eliciencia y su movimiento en el sistema educativo se calcularon y presentaron en los anexos 2 a 5. 
Aunque el grálico 4 muestra un incremento general en la instrucción a inicios del próximo siglo sólo cerca de $10 \%$ mayor que los indicadores base, este incremento no incorpora ninguna proyección de una tasa mayor de ingreso de nifos en edad para primer grado al sistema de instrucción primaria. El incremenlo en la ensefianza resulta sólo de una reducción de la deserción y no de nuevos flujos de nifios al sistema. Por lo tanto, en la medida en que las mejoras sugeridas en este trabajo se lleven realmente a cabo, estas proyecciones de ensefianza deberian ser consideradas como conservadoras, puesto que es probable que un sistema educalivo mejorado, así como niveles crecientes de ingreso (es decir, PIB percápita), estarán acompañados de una mayor demanda de educación por parte de aquellos seclores de la sociedad que aclualmente no participan en la educación primaria.

\section{Gráfico 4 \\ Producción de promovidos de 60 . grado}

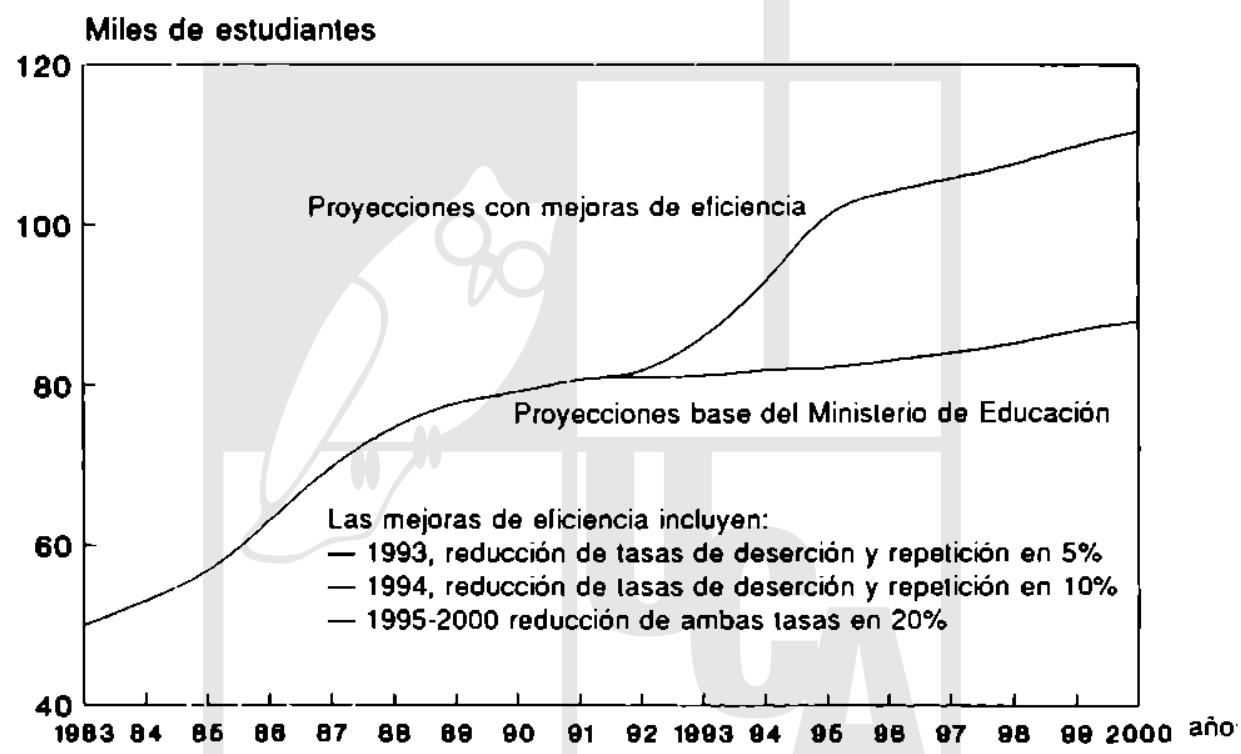

El incremento de la ensenanza en las escuelas primarias en EI Salvador, aunque representa sólo un $10 \%$ de aumento sobre la base, implica un incremento muy significalivo en el número de estudiantes que terminan sexto grado. La reducción de la deserción y la repetición, dado el número de nuevos entrantes a la instrucción primaria, implica un incremento de $30 \%$ en el número de estudiantes que completa sexio gra- 
do. El gráfico 4 indica la tendencia base y las proyecciones de tendencia, dadas las mejoras en eficiencia sefialadas en el número de esludiantes que completa sexto grado. El número de esludiantes que completa sexlo grado es un indicador muy importante de producción educacional, puesto que presenta la finalización de la instrucción primaria y por tanto la provisión de educación básica para los nifos de El Salvador.

Para calcular los costos de cumplir con estos objetivos, podemos multiplicar la canlidad de instrucción implícita en las actuales proyecciones base y asumir que el gobierno continuará gastando aproximadamente $\$ 65$ por estudiante de primaria y secundaria a lo largo del resto de la década.' Si asumimos que la instrucción sube por encima de la base como se muestra en el anexo A4 vrs. anexo A1 y que el gasio por estudiante sube constalemente (es decir, $8.5 \%$ cada ano) hasta $\$ 130$ en al ano 2000 , se esperaria que el gaslo en educación en El Salvador suba por encima de la proyección base de aproximadamente 960 millones de colones en 1992 a más de 2,303 (en términos reales, es decir, suponiendo que no hay inflación) para el ano 2000. La proyección de gastos crecientes en educación se presentan en el grálico 5 .

\section{Factibilldad de los objellvos}

Si asumimos que el PIB crece anualmente a aproximadamente $3.75 \%$ durante el periodo $1993-2000$, los coslos acarreados en educación pueden compararse con los niveles del PIB. Esta comparación se realiza en el cuadro 7, donde se presentan cuatro flujos de cosio. En el primer flujo de costo, se presenta la ensefanza primaria base al costo de $\$ 65$ por estudiante como porcentaje del PIB. El segundo flujo de coslo supone un nivel mejorado de educación, basado en las mejoras de eficiencia, pero también al costo de $\$ 65$ por estudiante. El tercer flujo de costos muestra los niveles actuales de ensehanza base, pero al cos10 de $\$ 130$ por estudiante. El cuarto flujo de costos muestra los coslos de elevar la instrucción mediante el incremento de la eliciencia y con coslos por estudiante subiendo hasla $\$ 130$ para el año 2000.

7 Las proyecciones de gasto total basadas en las proyecciones base darán cuenta sólo de las mejoras en eficiencia a nivel primario. Lo más simple es suponer que el gasto en educación secundaria y superior sigue siendo una proporción constante del gaslo en educación primaria, aunque el rápido crecimiento en el número de estudiantes que completa sexto grado previsto aquí implica necesariamente la necesidad de que el gasto en educación secundaria crezca todavia más rápidamente, a menos que la absorción de estudiantes de las escuelas secundarias privadas se incremente: 


\section{Grállca 5 \\ Elevaclón del gasto en educación}

Millones de colones de 1992.

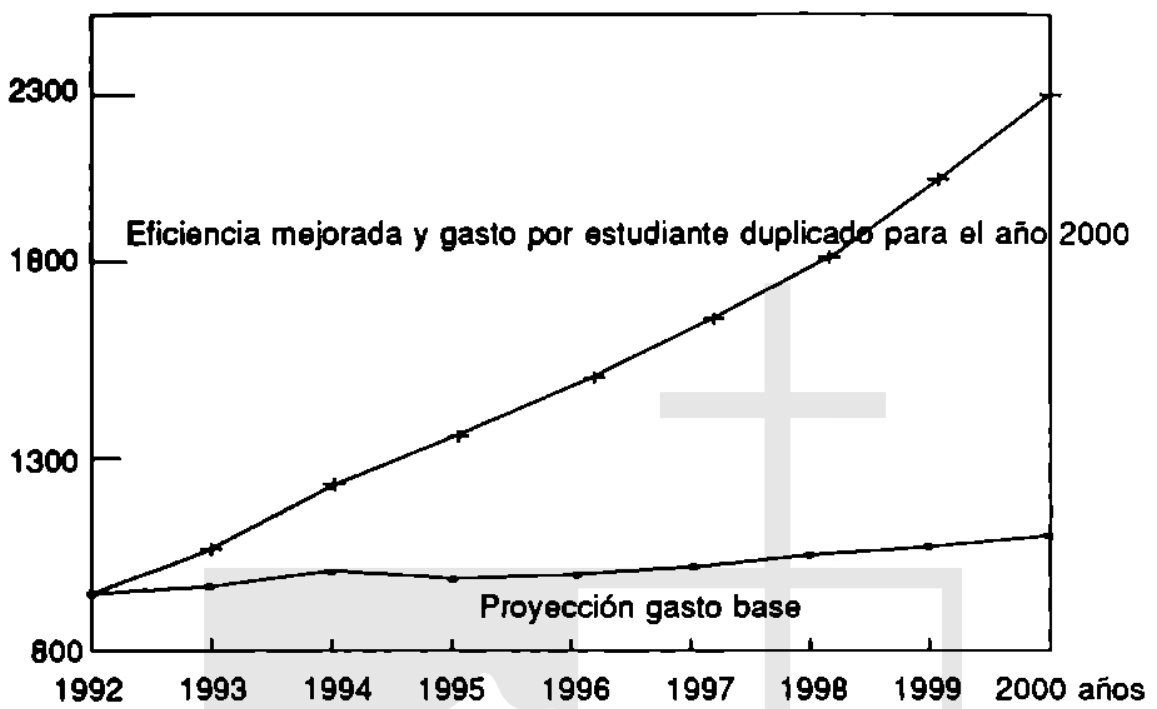

\section{Cuadro 7}

Proyecclones de costos de educaclón (Porcentajes del PIB)

\begin{tabular}{|c|c|c|c|c|c|c|c|c|}
\hline & 1993 & 1944 & 1995 & 1996 & 1997 & 1998 & 1999 & 2000 \\
\hline $\begin{array}{l}\text { 1. Enseñanza } \\
\text { base @ \$65 } \\
\text { por estudiante }\end{array}$ & 2.1 & 2.1 & 2.0 & 1.9 & 1.9 & 1.9 & 1.9 & 1.8 \\
\hline $\begin{array}{l}\text { 2. Niveles mejorados } \\
\text { de enseñanza @ } \\
\$ 65 \text { por estudiante }\end{array}$ & 2.1 & 2.2 & 2.2 & 2.1 & 2.1 & 2.1 & 2.0 & 2.0 \\
\hline $\begin{array}{l}\text { 3. Enseňanza Dase } \\
\text { @ \$130 por estu- } \\
\text { diante }\end{array}$ & 2.3 & 2.5 & 2.5 & 2.7 & 2.9 & 3.1 & 3.3 & 3.6 \\
\hline $\begin{array}{l}\text { 4. Niveles mejorados } \\
\text { de enseñanza } \\
\text { @ \$130 por estu- } \\
\text { diante }\end{array}$ & 2.3 & 2.6 & 2.7 & 2.9 & 3.1 & 3.3 & 3.6 & 3.9 \\
\hline
\end{tabular}

El gasto base del presupuesto de 1992 es aproximademente 720 colones por estudiante. El gasto mejorado por estudiante impliea un erecimiento anual de $8.5 \%$ en términos reales. 
Pudiera parecer muy ambicioso la elevación del nivel de gaslo en educación a casi $4 \%$ del PIB en El Salvador, puesto que es el doble del nivel actual. Sin embargo, tal nivel de gasto no debería ser descartado sin más. De los 57 paises incluidos en nueslra base de datos, 21 gastaban más del $4 \%$ de su PIB en educación durante el periodo de la muestra. De éstos, 8 tenian un ingreso percápita inferior al de El Salvador. Por ejemplo, duranle los ochenta, Madagascar gastó cerca del $7 \%$ de su PIB en educación pública, pero con un ingreso percápita (\$330) un poco más de un tercio que el de El Salvador. Tanzania, con un bajo ingreso percápita (\$249), gastaba 5.3\%; Malawi (\$173), 7.9\%; Egipto (\$622), $7.1 \%$; y Suazilandia $(\$ 842), 7.9 \%$. Si estos paises pobres pueden gastar $5 \%$ y más de su PIB en educación pública, no parece una idea demasiado remola que El Salvador pudiera lograr también un objetivo de gasto similar.

Desde una perspectiva presupuestaria, si se asume que la tasa de gasto del gobierno central seguirá siendo de aproximadamente $14 \%$ del PIB a lo largo del resto de la década, el gasto en educación, que era sólo alrededor de $15 \%$ del gasto tolal del gobierno central durante 1990 92 , tendria que subir a ligeramente más de un tercio de todo el gasto del gobierno central para el afno 2000, a fin de duplicar e! gasio por estudiante y lograr los objetivos máximos presentados en el cuadro 6 . Si el gasto base por estudiante (\$65) se mantuviera, el incremento en la ensefanza que ocurriría como resultado de la reducción de deserciones y repeticiones, requeriría que el gobierno mantuviera (aproximadamente) el porcentaje del presupuesto dedicado a educación. Las porciones necesarias del presupuesto que lendrian que dedicarse a educación se presentan en el cuadro 8.

Los incrementos en la porción del presupuesto dedicada a educación requeriria hacer dificiles elecciones, como se deduce de este cuadro. Entre las áreas cuyo gaslo habría que reducir están defensa, administración general, asuntos internacionales, orden público (es decir, policía, administración de juslicia y prisiones), infraestuctura física y otros gastos sociales. Asumiendo que cada una de estas áreas retiene su propia clientela política no se puede sugerir en este momenlo cuáles deberian ser recortadas a fin de dejar más espacio para el gasto en educación. Sin embargo, debe tenerse presente que en 1992 se espera que los pagos por intereses lleguen a $20 \%$ del presupuesio del gobierno central. Todavia no se sabe qué porción del presupuesto se requerirá para el pago de intereses durante el resto de la década. Si suponemos que los pagos por intereses conservarán su actual porción del presupuesto, podría ser baslante faclible que el gasto en educación se elevara a $28 \%$, y dejar $52 \%$ del presupuesto para los otros gastos de luncionamiento. 


\section{Cuadro 8 \\ Proyección de costos de educación \\ (Porcentajes del gasto del goblerno central)}

\begin{tabular}{|l|c|c|c|c|c|c|c|c|}
\hline & 1993 & 1944 & 1995 & 1996 & 1997 & 1998 & 1999 & 2000 \\
\hline $\begin{array}{l}\text { 1. Enseñanza } \\
\text { base @ \$65 } \\
\text { por estudiante }\end{array}$ & 15.0 & 15.3 & 14.2 & 14.0 & 13.8 & 13.5 & 13.4 & 13.2 \\
\hline $\begin{array}{l}\text { 2. Niveles mejorados } \\
\text { de enseñanza @ } \\
\$ 65 \text { por estudiante }\end{array}$ & 15.3 & 15.8 & 15.4 & 15.1 & 14.9 & 14.6 & 14.5 & 14.3 \\
\hline $\begin{array}{l}\text { 3. Enseñanza base } \\
\text { @ \$130 por estu- } \\
\text { diante }\end{array}$ & 16.3 & 18.0 & 18.2 & 19.4 & 20.7 & 22.0 & 23.7 & 25.5 \\
\hline $\begin{array}{l}\text { 4. Niveles mejorados } \\
\text { de enseñanza } \\
\text { @ \$130 por estu- } \\
\text { diante }\end{array}$ & 16.6 & 18.6 & 19.6 & 20.9 & 22.4 & 23.9 & 25.7 & 27.5 \\
\hline
\end{tabular}

El gasto base del presupuesto de 1992 es aproximadamente 720 colones por estudiante.

El gasto mejorado por estudiante implica un crecimiento anual de $8.5 \%$ en términos reales.

\section{Conclusiones}

La educación pública en El Salvador necesita mejorar grandemente. Tales mejoras requerirán una mejor adminisıración, cambios de política, mejor adiesıramiento para los maestros y más dinero. El gaslo es muy bajo comparado con normas inlernacionales. De hecho, el gaslo en educación pública es menos de un tercio de lo que cabria esperar, dado el nivel promedio de ingreso del pais. Ahora que la guerra ha lerminado, el gobierno se está concentrando en la reconstrucción de la infraestruclura de la nación. También debería prestarse atención a elevar la calidad de la educación en el pais.

Este trabajo ha hecho algunas comparaciones internacionales para arrojar alguna luz sobre las condiciones de la instrucción pública en EI Salvador. Usando esas comparaciones internacionales, este Irabajo ha eslablecido algunos objetivos un tanio ambiciosos, que EI Salvador deberia tratar de lograr. Comparando eslos objetivos con el rumbo probable que la economía salvadoreńa pueda lomar durante los próximos años, así como las condiciones de la tinanzas públicas de El Salvador, podemos concluir que esos objetivos son financieramente faclibles. 


\section{Problemas de anállsis y datos}

El análisis supone que todos los nifos en edad escolar asislen a las escuelas públicas; sin embargo, casi lodos los países del mundo envian algunos esludiantes a escuelas privadas. No hay ninguna fuente confiable de población estudiantil en los PMD, de manera que las eslimaciones que se hacen de población estudiantil pueden no ser muy exactas. El análisis internacional trala al gasto en educación pública y maestros como los únicos insumos del sistema educativo, ignorando otros insumos, como facilidades, yeso, escritorios y asistencia provista por comunidades locales. ${ }^{B}$

En El Salvador, una parte grande del pais ha estado controlada por las fuerzas rebeldes, que han proveido instrucción a los nif́os en esas áreas. Este análisis no anlicipa costos adicionales para el gobierno cenIral en el caso en que estas escuelas sean administradas en el futuro por el Ministerio de Educación. Aunque el rol que el Ministerio de Educación jugará en las anliguas zonas de combate lodavia es incierto, es de esperar que los costos del gobierno central se incrementen.

\section{REFERENCIAS BIBLIOGRAFICAS}

E.F. Denison (1962). The Sources of Economic Growth in the United States. New York: National Bureau of Economic Research.

M. Gallagher (1991). Rent Seeking and Economic Growth in Africa. Boulder: Westview Press.

O. Ogbu y M. Gallagher (1991). "On Public Expenditure and Delivery of Education in Sub-Saharan Africa". Comparative Education Review. vol. 35, \#2.

R. Ram (1986). "Causality between Income and Government Expenditure: A Broad International Perspective-. Public Finance \# 3.

....- (1987). -Wagner's Hypothesis in Time-Series and Cross-Section Perspectives: Evidence Irom 'Real' Dala for 115 Countries". Review of Economics and Statistics, mayo.

R. Solow (1957). "Technical Change and the Aggregate Production Function". Review of Economic and Statistics, agosto.

M.P. Todaro (1977). Economic Development in the Third World. New York: Longman.

A. Wagner (1890). Finanzwissenschaft. Leipzig.

a Ogbu y Gallagher (1991) señalan claramente que hay una gran variedad de insumos para la educación en PMD, incluyendo, entre otros: prolesores con diversos grados de calilicación, construociones escolares y otros insumos físicos, y la mezcla elicienle de recursos. Señalan también que las escuelas privadas, escuelas sostenidas por la comunidad, escuelas construidas por la comunidad, todas son parte de los recursos disponibles para educación, pero no son captados por las bases de datos internacionales de educación sobre los que se basan ésla y otras internacionales comparalivos de educación. 


\section{ANEXOS}

Cuadro A1

Indlcadores de educación en PMD

\begin{tabular}{|c|c|c|c|c|c|c|c|c|c|}
\hline & & \multicolumn{3}{|c|}{$\begin{array}{l}\text { Gasto en } \\
\text { educación }\end{array}$} & \multirow{2}{*}{$\begin{array}{l}\text { Estuds. } \\
\text { por } \\
\text { maestro }\end{array}$} & \multirow{2}{*}{$\begin{array}{c}\text { Progre- } \\
\text { sión } \\
\text { hasta } \\
40 . \\
\text { grado }\end{array}$} & \multirow{2}{*}{$\begin{array}{c}\text { Pepiti- } \\
\text { ción en } \\
\text { prima- } \\
\text { ria }\end{array}$} & \multirow{2}{*}{$\begin{array}{c}\text { Deser- } \\
\text { ción } \\
\text { en pri- } \\
\text { maria }\end{array}$} & \multirow{2}{*}{$\begin{array}{c}\text { Tasa } \\
\text { de } \\
\text { esco- } \\
\text { laridad } \\
\text { primaria }\end{array}$} \\
\hline & $\begin{array}{l}\text { Ingreso } \\
\text { percáp. }\end{array}$ & $\begin{array}{c}\% \\
\text { PIB }\end{array}$ & $\begin{array}{c}\text { per } \\
\text { cápita }\end{array}$ & $\begin{array}{c}\text { por } \\
\text { estud. }\end{array}$ & & & & & \\
\hline Argentina & 2158 & 3.9 & 84.16 & 316 & 20 & 76 & - & 24 & 108 \\
\hline Bangladesh & 157 & 1.1 & 1.73 & 9 & 50 & 28 & 18 & 72 & 62 \\
\hline Benin & 313 & 2.8 & 6.76 & 44 & 37 & 68 & 24 & 32 & 66 \\
\hline Bolivia & 509 & 1.1 & 5.60 & 21 & 27 & 55 & - & 45 & 87 \\
\hline Botswana & 1070 & 8.3 & 88.81 & 289 & 32 & 95 & 5 & 5 & 107 \\
\hline Brasil & 1984 & 3.6 & 71.42 & 282 & 24 & 60 & 20 & 40 & - \\
\hline Camerín & 885 & 4.3 & 37.61 & 131 & 50 & 84 & 30 & 16 & 108 \\
\hline China & 322 & 0.5 & 1.61 & 7 & 23 & 74 & - & 26 & 120 \\
\hline Chile & 1798 & 4.1 & 73.72 & - & - & 86 & 7 & 14 & - \\
\hline Colombia & 1269 & 3.0 & 38.07 & - & - & 63 & 14 & 37 & - \\
\hline Congo & 1035 & 0.9 & 9.31 & - & - & 91 & 30 & 9 & - \\
\hline Costa Rica & 1502 & 5.6 & 84.11 & - & - & B7 & 9 & 13 & - \\
\hline $\begin{array}{l}\text { Costa de } \\
\text { Martil }\end{array}$ & 862 & 2.9 & 25.00 & - & 38 & 88 & 25 & 12 & 71 \\
\hline $\begin{array}{l}\text { República } \\
\text { Dominicana }\end{array}$ & 958 & 2.2 & 21.08 & - & - & 55 & 15 & 45 & - \\
\hline Ecuador & 1220 & 3.9 & 47.58 & 134 & 35 & 76 & 9 & 24 & 117 \\
\hline Egipto & 622 & 7.5 & 46.65 & 156 & 32 & 80 & 3 & 20 & 87 \\
\hline El Salvador" & 838 & 1.8 & 15.08 & 65 & 45 & 58 & 8 & 42 & 75 \\
\hline Etiopla & 119 & 1.1 & 1.31 & 12 & 55 & 50 & 7 & 50 & 35 \\
\hline Fiji & 1722 & 6.5 & 112.79 & 327 & 29 & 96 & 4 & 4 & 129 \\
\hline Gustemala & 1087 & 3.4 & 36.96 & - & - & 64 & 14 & 36 & - \\
\hline Honduras & 752 & 3.4 & 25.57 & 83 & 38 & 50 & 16 & 50 & 102 \\
\hline Hungrla & 2178 & 4.3 & 93.65 & - & - & 97 & 3 & 3 & - \\
\hline India & 292 & 2.8 & 8.18 & 35 & 57 & 57 & - & 43 & 95 \\
\hline Indonesia & 535 & 2.3 & 12.30 & - & - & 87 & 9 & 13 & - \\
\hline Jordania & 1186 & 6.8 & 80.62 & 187 & 32 & 97 & 4 & 3 & 99 \\
\hline Kenya & 365 & 4.1 & 14.78 & 47 & 36 & 74 & 13 & 26 & 101 \\
\hline $\begin{array}{l}\text { Corea del } \\
\text { Sur }\end{array}$ & 2557 & 5.5 & 139.36 & - & - & 98 & 0 & 2 & - \\
\hline Madagascar & 331 & 7.1 & 23.50 & - & - & - & - & - & - \\
\hline Malawi & 173 & 5.4 & 9.34 & 60 & 63 & 57 & 17 & 43 & 63 \\
\hline
\end{tabular}




\begin{tabular}{|l|r|r|r|r|r|r|r|r|r|}
\hline Mali & 207 & 1.0 & 2.07 & 29 & 37 & 71 & 30 & 29 & 23 \\
Mauricio & 1337 & 3.7 & 49.47 & 200 & 21 & 97 & 7 & 3 & 107 \\
México & 2214 & 3.2 & 70.85 & 203 & 35 & 83 & 10 & 17 & 119 \\
Marruecos & 770 & 4.3 & 32.73 & 142 & 32 & 87 & 25 & 13 & 79 \\
Nepal & 164 & 0.7 & 1.15 & 5 & 41 & - & - & - & 78 \\
Nigeria & 765 & 2.3 & 17.59 & 62 & 39 & 81 & - & 19 & 88 \\
Paquistán & 340 & 1.7 & 5.61 & 39 & 38 & 50 & - & 50 & 50 \\
Panamá & 1934 & 6.0 & 116.04 & 373 & 22 & 87 & 12 & 13 & 105 \\
Paraguay & 1290 & 2.1 & 27.09 & 99 & 25 & 75 & 12 & 25 & 103 \\
Perú & 1116 & 3.9 & 43.52 & 121 & 37 & 84 & 17 & 16 & 117 \\
Filipinas & 666 & 2.9 & 19.65 & 55 & 31 & 77 & 2 & 23 & 107 \\
Polonia & 1874 & 3.9 & 73.08 & 328 & 16 & 98 & 3 & 2 & 101 \\
Portugal & 2659 & 3.6 & 97.05 & - & - & - & 19 & - & - \\
Ruanda & 282 & 2.9 & 8.18 & 50 & 56 & 79 & 12 & 21 & 64 \\
Senegal & 495 & 1.5 & 7.67 & 49 & 46 & 91 & 16 & 9 & 57 \\
Sierra Leona & 331 & 1.2 & 3.97 & - & - & - & - & - & - \\
Sri Lanka & 363 & 2.1 & 7.80 & 27 & 16 & 98 & 10 & 2 & 103 \\
Sudán & 401 & 4.3 & 17.24 & 113 & 34 & 78 & 0 & 22 & 50 \\
Suazilandia & 842 & 7.9 & 66.52 & 190 & 34 & 84 & 13 & 16 & 106 \\
Tanzania & 249 & 5.3 & 13.07 & 65 & 38 & 89 & 2 & 11 & 75 \\
Tailandia & 855 & 3.3 & 28.21 & 122 & 21 & 84 & 8 & 16 & 96 \\
Túnez & 1237 & 4.5 & 55.67 & 188 & 30 & 93 & 21 & 7 & 113 \\
Turquia & 1246 & 1.0 & 12.46 & - & - & 97 & 8 & 3 & - \\
Uruguay & 2505 & 2.7 & 67.64 & - & - & 97 & 11 & 3 & - \\
Yugoslavia & 2732 & 4.1 & 112.01 & - & - & 98 & 2 & 2 & - \\
Zaire & 383 & 0.2 & 0.77 & 3 & 42 & 74 & 15 & 26 & 83 \\
Zambia & 455 & 4.5 & 20.70 & 76 & 48 & 100 & 2 & 0 & 96 \\
Zimbawe & 699 & 4.3 & 30.06 & 81 & 41 & 84 & 0 & 16 & 132 \\
\hline
\end{tabular}

* Los datos de El Salvador son de 1991. En 1980, El Salvador dedicó $3.9 \%$ del PIB a educación. Los datos para el resto de paises provienen de información promedio para la década 1980-89.

Fuente: Banco Mundial (World Tables), diskettes STARS, 1991.

El gasto por estudiante se estimó dividiendo el gasto nacional en educación entre la población estudiantil estimada.

La población estudiantil se estimó tomando promedios ponderados de las tasas de escolaridad primaria y secundaria y aplicando éstas a la proporción de población nacional menor de 15 años.

A menos que se indique de otro modo, todos los gastos están expresados en dólares de 1985 . 
Cuadro A2

Estimaciones base del Ministerio de Educación

\begin{tabular}{|c|c|c|c|c|c|c|c|c|c|c|c|c|c|c|c|c|c|c|}
\hline Base & 1983 & 1984 & 1985 & 1986 & 1987 & 1988 & 1989 & 1990 & 1991 & 1992 & 1993 & 1994 & 1995 & 1996 & 1997 & 1998 & 1999 & 2000 \\
\hline $\begin{array}{l}\text { Nuevos } \\
\text { ingresos }\end{array}$ & 187 & 188 & 197 & 206 & 198 & 200 & 201 & 203 & 205 & 208 & 211 & 214 & 217 & 222 & 229 & 234 & 241 & 247 \\
\hline \multicolumn{19}{|c|}{ hay algunos errores de aproximación } \\
\hline \multicolumn{19}{|l|}{ GRADO } \\
\hline $\begin{array}{l}\text { PRIMERO } \\
\text { Promoción } \\
\text { Repetición } \\
\text { Deserción } \\
\text { Promoción } \\
\text { sin mejora }\end{array}$ & $\begin{array}{r}229 \\
139 \\
42 \\
48 \\
10\end{array}$ & $\begin{array}{r}229 \\
145 \\
41 \\
43 \\
6\end{array}$ & $\begin{array}{r}240 \\
151 \\
43 \\
46 \\
8\end{array}$ & $\begin{array}{r}246 \\
154 \\
40 \\
52 \\
1\end{array}$ & $\begin{array}{r}236 \\
151 \\
38 \\
47 \\
1\end{array}$ & $\begin{array}{r}239 \\
153 \\
39 \\
47 \\
0\end{array}$ & $\begin{array}{r}240 \\
154 \\
39 \\
47 \\
0\end{array}$ & $\begin{array}{r}242 \\
155 \\
39 \\
48 \\
1\end{array}$ & $\begin{array}{r}245 \\
157 \\
40 \\
48 \\
3\end{array}$ & $\begin{array}{r}248 \\
159 \\
40 \\
49 \\
2\end{array}$ & $\begin{array}{r}252 \\
161 \\
41 \\
50 \\
2\end{array}$ & $\begin{array}{r}255 \\
164 \\
41 \\
50 \\
3\end{array}$ & $\begin{array}{r}259 \\
166 \\
42 \\
51 \\
3\end{array}$ & $\begin{array}{r}265 \\
170 \\
43 \\
52 \\
4\end{array}$ & $\begin{array}{r}273 \\
175 \\
44 \\
54 \\
5\end{array}$ & $\begin{array}{r}279 \\
179 \\
45 \\
55 \\
5\end{array}$ & $\begin{array}{r}288 \\
184 \\
47 \\
57 \\
6\end{array}$ & $\begin{array}{r}295 \\
189 \\
48 \\
58 \\
6\end{array}$ \\
\hline $\begin{array}{l}\text { SEGUNDO } \\
\text { Promoción } \\
\text { Repetición } \\
\text { Deserción } \\
\text { Promoción } \\
\text { sin mejora }\end{array}$ & $\begin{array}{r}142 \\
112 \\
13 \\
17 \\
9\end{array}$ & $\begin{array}{r}152 \\
123 \\
13 \\
16 \\
12\end{array}$ & $\begin{array}{r}157 \\
128 \\
14 \\
15 \\
6\end{array}$ & $\begin{array}{r}167 \\
131 \\
14 \\
22 \\
2\end{array}$ & $\begin{array}{r}164 \\
130 \\
14 \\
20 \\
1\end{array}$ & $\begin{array}{r}167 \\
133 \\
14 \\
20 \\
0\end{array}$ & $\begin{array}{r}168 \\
134 \\
14 \\
20 \\
2\end{array}$ & $\begin{array}{r}168 \\
134 \\
14 \\
20 \\
1\end{array}$ & $\begin{array}{r}168 \\
134 \\
14 \\
20 \\
1\end{array}$ & $\begin{array}{r}171 \\
136 \\
14 \\
21 \\
2\end{array}$ & $\begin{array}{r}174 \\
138 \\
15 \\
21 \\
2\end{array}$ & $\begin{array}{r}176 \\
140 \\
15 \\
21 \\
2\end{array}$ & $\begin{array}{r}178 \\
142 \\
15 \\
21 \\
2\end{array}$ & $\begin{array}{r}181 \\
144 \\
15 \\
22 \\
3\end{array}$ & $\begin{array}{r}186 \\
148 \\
16 \\
22 \\
4\end{array}$ & $\begin{array}{r}190 \\
151 \\
16 \\
23 \\
4\end{array}$ & $\begin{array}{r}195 \\
155 \\
17 \\
23 \\
4\end{array}$ & $\begin{array}{r}201 \\
159 \\
18 \\
24 \\
4\end{array}$ \\
\hline $\begin{array}{l}\text { TERCERO } \\
\text { Promoción } \\
\text { Repeticion } \\
\text { Deserción } \\
\text { Promoción } \\
\text { sin mejora }\end{array}$ & $\begin{array}{r}110 \\
91 \\
7 \\
12 \\
11\end{array}$ & $\begin{array}{r}119 \\
101 \\
8 \\
10 \\
11\end{array}$ & $\begin{array}{r}131 \\
110 \\
9 \\
12 \\
9\end{array}$ & $\begin{array}{r}137 \\
113 \\
8 \\
16 \\
3\end{array}$ & $\begin{array}{r}137 \\
114 \\
8 \\
15 \\
1\end{array}$ & $\begin{array}{r}141 \\
118 \\
8 \\
15 \\
4\end{array}$ & $\begin{array}{r}140 \\
117 \\
8 \\
15 \\
0\end{array}$ & $\begin{array}{r}141 \\
118 \\
8 \\
15 \\
0\end{array}$ & $\begin{array}{r}141 \\
118 \\
8 \\
15 \\
0\end{array}$ & $\begin{array}{r}143 \\
119 \\
9 \\
15 \\
0\end{array}$ & $\begin{array}{r}145 \\
120 \\
9 \\
16 \\
1\end{array}$ & $\begin{array}{r}147 \\
122 \\
9 \\
16 \\
2\end{array}$ & $\begin{array}{r}149 \\
124 \\
9 \\
16 \\
3\end{array}$ & $\begin{array}{r}150 \\
125 \\
9 \\
9 \\
16 \\
1\end{array}$ & $\begin{array}{r}153 \\
127 \\
9 \\
17 \\
2\end{array}$ & $\begin{array}{r}156 \\
130 \\
9 \\
17 \\
3\end{array}$ & $\begin{array}{r}161 \\
134 \\
10 \\
17 \\
3\end{array}$ & $\begin{array}{r}165 \\
138 \\
10 \\
17 \\
4\end{array}$ \\
\hline $\begin{array}{l}\text { CUARTO } \\
\text { Promoción } \\
\text { Repetición } \\
\text { Deserción } \\
\text { Promoción } \\
\text { sin mejora }\end{array}$ & $\begin{array}{r}85 \\
70 \\
5 \\
10 \\
1\end{array}$ & $\begin{array}{r}95 \\
81 \\
5 \\
9 \\
9\end{array}$ & $\begin{array}{r}106 \\
90 \\
5 \\
11 \\
9\end{array}$ & $\begin{array}{r}115 \\
94 \\
5 \\
16 \\
4\end{array}$ & $\begin{array}{r}118 \\
98 \\
5 \\
15 \\
0\end{array}$ & $\begin{array}{r}119 \\
99 \\
5 \\
15 \\
0\end{array}$ & $\begin{array}{r}122 \\
101 \\
5 \\
16 \\
0\end{array}$ & $\begin{array}{r}123 \\
102 \\
5 \\
16 \\
0\end{array}$ & $\begin{array}{r}123 \\
102 \\
5 \\
16 \\
0\end{array}$ & $\begin{array}{r}124 \\
103 \\
5 \\
16 \\
1\end{array}$ & $\begin{array}{r}124 \\
103 \\
5 \\
16 \\
1\end{array}$ & $\begin{array}{r}166 \\
104 \\
46 \\
16 \\
2\end{array}$ & \begin{tabular}{r|}
127 \\
105 \\
6 \\
16 \\
2
\end{tabular} & $\begin{array}{r}130 \\
107 \\
6 \\
17 \\
1\end{array}$ & $\begin{array}{r}131 \\
108 \\
6 \\
17 \\
1\end{array}$ & $\begin{array}{r}133 \\
110 \\
6 \\
17 \\
1\end{array}$ & $\begin{array}{r}137 \\
113 \\
6 \\
18 \\
3\end{array}$ & $\begin{array}{r}140 \\
116 \\
6 \\
18 \\
3\end{array}$ \\
\hline $\begin{array}{l}\text { QUINTO } \\
\text { Promoción } \\
\text { Repetición } \\
\text { Deserción } \\
\text { Promoción } \\
\text { sin mejora }\end{array}$ & $\begin{array}{r}72 \\
60 \\
3 \\
9 \\
0\end{array}$ & $\begin{array}{r}75 \\
65 \\
3 \\
7 \\
5\end{array}$ & $\begin{array}{r}84 \\
73 \\
3 \\
8 \\
10\end{array}$ & $\begin{array}{r}93 \\
79 \\
3 \\
11 \\
6\end{array}$ & $\begin{array}{r}101 \\
89 \\
3 \\
9 \\
10\end{array}$ & $\begin{array}{r}102 \\
89 \\
3 \\
10 \\
5\end{array}$ & $\begin{array}{r}104 \\
91 \\
3 \\
10 \\
3\end{array}$ & $\begin{array}{r}105 \\
92 \\
3 \\
10 \\
3\end{array}$ & $\begin{array}{r}105 \\
92 \\
3 \\
10 \\
1\end{array}$ & $\begin{array}{r}105 \\
92 \\
3 \\
10 \\
1\end{array}$ & $\begin{array}{r}105 \\
92 \\
3 \\
10 \\
1\end{array}$ & $\begin{array}{r}105 \\
92 \\
3 \\
10 \\
0\end{array}$ & $\begin{array}{r}106 \\
93 \\
3 \\
10 \\
1\end{array}$ & $\begin{array}{r}109 \\
95 \\
3 \\
11 \\
2\end{array}$ & $\begin{array}{r}110 \\
96 \\
3 \\
11 \\
1\end{array}$ & $\begin{array}{r}112 \\
98 \\
3 \\
11 \\
2\end{array}$ & $\begin{array}{r}113 \\
99 \\
3 \\
11 \\
1\end{array}$ & $\begin{array}{r}116 \\
102 \\
3 \\
11 \\
3\end{array}$ \\
\hline $\begin{array}{l}\text { SEXTO } \\
\text { Promoción } \\
\text { Repetición } \\
\text { Deserción }\end{array}$ & $\begin{array}{r}62 \\
50 \\
2 \\
10\end{array}$ & $\begin{array}{r}62 \\
53 \\
2 \\
7\end{array}$ & $\begin{array}{r}65 \\
56 \\
2 \\
7\end{array}$ & $\begin{array}{r}75 \\
63 \\
2 \\
10\end{array}$ & $\begin{array}{r}81 \\
70 \\
2 \\
9\end{array}$ & $\begin{array}{r}86 \\
75 \\
2 \\
9\end{array}$ & $\begin{array}{r}90 \\
78 \\
2 \\
10\end{array}$ & $\begin{array}{r}91 \\
79 \\
2 \\
10\end{array}$ & $\begin{array}{r}93 \\
81 \\
2 \\
10\end{array}$ & \begin{tabular}{r|r}
93 \\
81 \\
2 \\
10
\end{tabular} & $\begin{array}{r}93 \\
81 \\
2 \\
10\end{array}$ & $\begin{array}{r}94 \\
82 \\
2 \\
10\end{array}$ & $\begin{array}{r}94 \\
82 \\
2 \\
10\end{array}$ & $\begin{array}{r}95 \\
83 \\
2 \\
10\end{array}$ & $\begin{array}{r}97 \\
84 \\
2 \\
11\end{array}$ & $\begin{array}{r}98 \\
85 \\
2 \\
11\end{array}$ & $\begin{array}{r}100 \\
87 \\
2 \\
11\end{array}$ & $\begin{array}{r}101 \\
88 \\
2 \\
11\end{array}$ \\
\hline $\begin{array}{l}\text { TOTAL } \\
\text { AÑOS DE } \\
\text { INSTRUC- } \\
\text { CION } \\
\ldots\end{array}$ & 700 & 732 & 783 & 833 & 837 & 854 & 864 & 870 & 875 & 884 & 893 & 943 & 913 & 930 & 950 & 968 & 994 & 1018 \\
\hline $\begin{array}{l}\text { Promoción } \\
60 . \text { grado, } \\
\text { total afios }\end{array}$ & 7 & 7 & 7 & 8 & 8 & 9 & 9 & 9 & 9 & 9 & 9 & 9 & 9 & 9 & 9 & 9 & 9 & 9 \\
\hline
\end{tabular}


Cuadro A3

Mejoras en eficiencia sobre la base

\begin{tabular}{|c|c|c|c|c|c|c|c|c|c|c|c|c|c|c|c|c|c|c|}
\hline \multirow{3}{*}{\begin{tabular}{|l|} 
Reducción \\
desperdicio \\
$1993=5 \%$ \\
$1994=10 \%$ \\
$1995-$ \\
$2000=20 \%$ \\
\end{tabular}} & & & & & & & & & & & & & & & & & & \\
\hline & 1983 & 1984 & 1985 & 1986 & 1987 & 1988 & 1989 & 1990 & 1991 & 1992 & 1993 & 1994 & 1995 & 1996 & 1997 & 1998 & 1999 & 2000 \\
\hline & \multicolumn{18}{|c|}{$\begin{array}{l}\text { Porcentajes de } \\
\text { ingreso al grado }\end{array}$} \\
\hline $\begin{array}{l}\text { PRIMERO } \\
\text { Promocion } \\
\text { Repeticion } \\
\text { Deserción } \\
\text { Promocion } \\
\text { sin mejora }\end{array}$ & $\begin{array}{r}61 \\
18 \\
21 \\
4\end{array}$ & $\begin{array}{r}63 \\
18 \\
19 \\
3\end{array}$ & $\begin{array}{r}63 \\
18 \\
19 \\
3\end{array}$ & $\begin{array}{r}63 \\
16 \\
21 \\
0\end{array}$ & $\begin{array}{r}64 \\
16 \\
20 \\
0\end{array}$ & $\begin{array}{r}64 \\
16 \\
20 \\
0\end{array}$ & $\begin{array}{r}64 \\
16 \\
20 \\
0\end{array}$ & $\begin{array}{r}64 \\
16 \\
20 \\
0\end{array}$ & $\begin{array}{r}64 \\
16 \\
20 \\
1\end{array}$ & $\begin{array}{r}64 \\
16 \\
20 \\
1\end{array}$ & $\begin{array}{r}66 \\
15 \\
19 \\
1\end{array}$ & $\begin{array}{r}68 \\
14 \\
18 \\
1\end{array}$ & $\begin{array}{r}71 \\
13 \\
16 \\
1\end{array}$ & $\begin{array}{r}71 \\
13 \\
16 \\
1\end{array}$ & $\begin{array}{r}71 \\
13 \\
16 \\
1\end{array}$ & $\begin{array}{r}71 \\
13 \\
16 \\
1\end{array}$ & $\begin{array}{r}71 \\
13 \\
16 \\
2\end{array}$ & $\begin{array}{r}71 \\
13 \\
16 \\
2\end{array}$ \\
\hline $\begin{array}{l}\text { SEGUNDO } \\
\text { Promoción } \\
\text { Repetición } \\
\text { Deserción } \\
\text { Promoción } \\
\text { sin mejora }\end{array}$ & $\begin{array}{r}79 \\
9 \\
12 \\
6\end{array}$ & $\begin{array}{r}81 \\
9 \\
11 \\
8\end{array}$ & $\begin{array}{r}82 \\
9 \\
10 \\
4\end{array}$ & $\begin{array}{r}78 \\
8 \\
13 \\
1\end{array}$ & $\begin{array}{r}79 \\
9 \\
12 \\
1\end{array}$ & $\begin{array}{r}80 \\
8 \\
12 \\
0\end{array}$ & $\begin{array}{r}80 \\
8 \\
12 \\
1\end{array}$ & $\begin{array}{r}80 \\
8 \\
12 \\
1\end{array}$ & $\begin{array}{r}80 \\
8 \\
12 \\
1\end{array}$ & $\begin{array}{r}80 \\
8 \\
12 \\
1\end{array}$ & $\begin{array}{r}80 \\
8 \\
11 \\
1\end{array}$ & $\begin{array}{r}82 \\
8 \\
11 \\
1\end{array}$ & $\begin{array}{r}84 \\
7 \\
9 \\
1\end{array}$ & $\begin{array}{r}84 \\
7 \\
10 \\
1\end{array}$ & $\begin{array}{r}84 \\
7 \\
9 \\
2\end{array}$ & $\begin{array}{r}84 \\
7 \\
10 \\
2\end{array}$ & $\begin{array}{r}84 \\
7 \\
9 \\
2\end{array}$ & $\begin{array}{r}83 \\
7 \\
10 \\
2\end{array}$ \\
\hline $\begin{array}{l}\text { TERCERO } \\
\text { Promoción } \\
\text { Repetición } \\
\text { Deserción } \\
\text { Promoción } \\
\text { sin mejora }\end{array}$ & $\begin{array}{r}83 \\
6 \\
11 \\
10\end{array}$ & $\begin{array}{r}85 \\
7 \\
8 \\
9\end{array}$ & $\begin{array}{r}84 \\
7 \\
9 \\
7\end{array}$ & $\begin{array}{r}82 \\
6 \\
12 \\
2\end{array}$ & $\begin{array}{r}83 \\
6 \\
11 \\
1\end{array}$ & $\begin{array}{r}84 \\
6 \\
11 \\
3\end{array}$ & $\begin{array}{r}84 \\
6 \\
11 \\
0\end{array}$ & $\begin{array}{r}84 \\
6 \\
11 \\
0\end{array}$ & $\begin{array}{r}84 \\
6 \\
11 \\
0\end{array}$ & $\begin{array}{r}83 \\
6 \\
10 \\
0\end{array}$ & $\begin{array}{r}84 \\
6 \\
10 \\
1\end{array}$ & $\begin{array}{r}85 \\
6 \\
10 \\
1\end{array}$ & $\begin{array}{r}87 \\
5 \\
9 \\
2\end{array}$ & $\begin{array}{r}87 \\
5 \\
9 \\
1\end{array}$ & $\begin{array}{r}86 \\
5 \\
9 \\
1\end{array}$ & $\begin{array}{r}87 \\
5 \\
9 \\
2\end{array}$ & $\begin{array}{r}87 \\
5 \\
8 \\
1\end{array}$ & $\begin{array}{r}87 \\
5 \\
8 \\
2\end{array}$ \\
\hline $\begin{array}{l}\text { CUAATO } \\
\text { Promoción } \\
\text { Repetición } \\
\text { Deserción } \\
\text { Promoción } \\
\text { sin mejora }\end{array}$ & $\begin{array}{r}82 \\
6 \\
12 \\
1\end{array}$ & $\begin{array}{r}85 \\
5 \\
9 \\
9\end{array}$ & $\begin{array}{r}85 \\
5 \\
10 \\
8\end{array}$ & $\begin{array}{r}82 \\
4 \\
14 \\
3\end{array}$ & $\begin{array}{r}83 \\
4 \\
13 \\
0\end{array}$ & $\begin{array}{r}83 \\
4 \\
13 \\
0\end{array}$ & $\begin{array}{r}83 \\
4 \\
13 \\
0\end{array}$ & $\begin{array}{r}83 \\
4 \\
13 \\
0\end{array}$ & $\begin{array}{r}83 \\
4 \\
13 \\
0\end{array}$ & $\begin{array}{r}83 \\
4 \\
13 \\
1\end{array}$ & $\begin{array}{r}84 \\
4 \\
12 \\
1\end{array}$ & $\begin{array}{r}66 \\
25 \\
9 \\
1\end{array}$ & $\begin{array}{r}86 \\
4 \\
10 \\
1\end{array}$ & $\begin{array}{r}86 \\
4 \\
10 \\
1\end{array}$ & $\begin{array}{r}86 \\
4 \\
10 \\
1\end{array}$ & $\begin{array}{r}86 \\
4 \\
10 \\
1\end{array}$ & $\begin{array}{r}86 \\
4 \\
11 \\
2\end{array}$ & $\begin{array}{r}86 \\
3 \\
10 \\
2\end{array}$ \\
\hline $\begin{array}{l}\text { QUINTO } \\
\text { Promoción } \\
\text { Repetición } \\
\text { Deserción } \\
\text { Promoción } \\
\text { sin merjora }\end{array}$ & $\begin{array}{r}83 \\
4 \\
13 \\
0\end{array}$ & $\begin{array}{r}87 \\
4 \\
9 \\
7\end{array}$ & $\begin{array}{r}87 \\
4 \\
10 \\
12\end{array}$ & $\begin{array}{r}85 \\
3 \\
12 \\
6\end{array}$ & $\begin{array}{r}88 \\
3 \\
9 \\
10\end{array}$ & $\begin{array}{r}87 \\
3 \\
10 \\
5\end{array}$ & $\begin{array}{r}88 \\
3 \\
10 \\
3\end{array}$ & $\begin{array}{r}88 \\
3 \\
10 \\
3\end{array}$ & $\begin{array}{r}88 \\
3 \\
10 \\
1\end{array}$ & $\begin{array}{r}88 \\
3 \\
10 \\
1\end{array}$ & $\begin{array}{r}88 \\
3 \\
9 \\
1\end{array}$ & $\begin{array}{r}89 \\
3 \\
9 \\
0\end{array}$ & $\begin{array}{r}90 \\
2 \\
8 \\
1\end{array}$ & $\begin{array}{r}90 \\
2 \\
8 \\
1\end{array}$ & $\begin{array}{r}90 \\
2 \\
8 \\
1\end{array}$ & $\begin{array}{r}90 \\
2 \\
8 \\
1\end{array}$ & $\begin{array}{r}90 \\
2 \\
8 \\
1\end{array}$ & $\begin{array}{r}90 \\
2 \\
8 \\
2\end{array}$ \\
\hline $\begin{array}{l}\text { SEXTO } \\
\text { Promoción } \\
\text { Repetición }\end{array}$ & $\begin{array}{r}81 \\
3\end{array}$ & $\begin{array}{r}85 \\
3\end{array}$ & $\begin{array}{r}86 \\
3\end{array}$ & $\begin{array}{r}84 \\
3\end{array}$ & $\begin{array}{r}86 \\
2\end{array}$ & $\begin{array}{r}87 \\
2\end{array}$ & $\begin{array}{r}87 \\
2\end{array}$ & $\begin{array}{r}87 \\
2\end{array}$ & $\begin{array}{r}87 \\
2\end{array}$ & $\begin{array}{r}87 \\
2\end{array}$ & $\begin{array}{r}88 \\
2\end{array}$ & $\begin{array}{r}88 \\
2\end{array}$ & $\begin{array}{r}90 \\
2\end{array}$ & $\begin{array}{r}90 \\
2\end{array}$ & $\begin{array}{r}89 \\
2\end{array}$ & $\begin{array}{r}89 \\
2\end{array}$ & $\begin{array}{r}89 \\
2\end{array}$ & $\begin{array}{r}90 \\
2\end{array}$ \\
\hline Deserción & 16 & 11 & 11 & 13 & 11 & 10 & 11 & 11 & 11 & 11 & 10 & 10 & 9 & 8 & 9 & 9 & 9 & 9 \\
\hline
\end{tabular}


Cuadro A4

Mejoras en eficiencia sobre la base

\begin{tabular}{|c|c|c|c|c|c|c|c|c|c|c|c|c|c|c|c|c|c|c|}
\hline $\begin{array}{l}\text { Reducción } \\
\text { desperdiclo }\end{array}$ & 1983 & 1984 & 1985 & 1986 & 1987 & 1988 & 1989 & 1990 & 1991 & 1992 & 1993 & 1994 & 1995 & 1996 & 1997 & 1998 & 1999 & 2000 \\
\hline \multicolumn{19}{|c|}{$1993=5 \%, 1994=10 \%, 1995-2000-20 \%$} \\
\hline $\begin{array}{l}\text { Nuevos } \\
\text { ingresos }\end{array}$ & 187 & 188 & 197 & 206 & 198 & 200 & 201 & 203 & 205 & 208 & 211 & 214 & 217 & 222 & 229 & 234 & 241 & 247 \\
\hline \multicolumn{19}{|c|}{ hay algunos errores de aproximacion } \\
\hline \multicolumn{19}{|l|}{ GRADO } \\
\hline $\begin{array}{l}\text { PRIMERO } \\
\text { Promoción } \\
\text { Repeticion } \\
\text { Deserción } \\
\text { Promoción } \\
\text { sin mejora }\end{array}$ & $\begin{array}{r}229 \\
139 \\
42 \\
48 \\
10\end{array}$ & $\begin{array}{r}229 \\
145 \\
41 \\
43 \\
6\end{array}$ & $\begin{array}{r}240 \\
151 \\
43 \\
46 \\
8\end{array}$ & $\begin{array}{r}246 \\
154 \\
40 \\
52 \\
1\end{array}$ & $\begin{array}{r}236 \\
151 \\
38 \\
47 \\
1\end{array}$ & $\begin{array}{r}239 \\
153 \\
39 \\
47 \\
0\end{array}$ & $\begin{array}{r}240 \\
154 \\
39 \\
47 \\
0\end{array}$ & $\begin{array}{r}242 \\
155 \\
39 \\
48 \\
1\end{array}$ & $\begin{array}{r}245 \\
157 \\
40 \\
48 \\
3\end{array}$ & $\begin{array}{r}248 \\
159 \\
40 \\
49 \\
2\end{array}$ & $\begin{array}{r}250 \\
164 \\
39 \\
47 \\
2\end{array}$ & $\begin{array}{r}250 \\
170 \\
36 \\
44 \\
3\end{array}$ & $\begin{array}{r}249 \\
178 \\
32 \\
39 \\
2\end{array}$ & $\begin{array}{r}255 \\
182 \\
33 \\
40 \\
3\end{array}$ & $\begin{array}{r}263 \\
187 \\
34 \\
42 \\
4\end{array}$ & $\begin{array}{r}269 \\
192 \\
35 \\
42 \\
4\end{array}$ & $\begin{array}{r}277 \\
197 \\
36 \\
44 \\
5\end{array}$ & $\begin{array}{r}284 \\
202 \\
37 \\
45 \\
5\end{array}$ \\
\hline $\begin{array}{l}\text { SEGUNDO } \\
\text { Promoción } \\
\text { Repetición } \\
\text { Deserción } \\
\text { Promoción } \\
\text { sin mejora }\end{array}$ & $\begin{array}{r}142 \\
112 \\
13 \\
17 \\
9\end{array}$ & $\begin{array}{r}152 \\
123 \\
13 \\
16 \\
12\end{array}$ & $\begin{array}{r}157 \\
128 \\
14 \\
15 \\
6\end{array}$ & $\begin{array}{r}167 \\
131 \\
14 \\
22 \\
2\end{array}$ & $\begin{array}{r}164 \\
130 \\
14 \\
20 \\
1\end{array}$ & $\begin{array}{r}167 \\
133 \\
14 \\
20 \\
0\end{array}$ & $\begin{array}{r}168 \\
134 \\
14 \\
20 \\
2\end{array}$ & $\begin{array}{r}168 \\
134 \\
14 \\
20 \\
1\end{array}$ & $\begin{array}{r}168 \\
134 \\
14 \\
20 \\
1\end{array}$ & $\begin{array}{r}171 \\
136 \\
14 \\
21 \\
2\end{array}$ & $\begin{array}{r}177 \\
142 \\
14 \\
20 \\
2\end{array}$ & $\begin{array}{r}181 \\
148 \\
14 \\
19 \\
2\end{array}$ & $\begin{array}{r}188 \\
158 \\
13 \\
18 \\
2\end{array}$ & $\begin{array}{r}192 \\
160 \\
13 \\
19 \\
3\end{array}$ & $\begin{array}{r}197 \\
165 \\
14 \\
19 \\
3\end{array}$ & $\begin{array}{r}201 \\
168 \\
14 \\
19 \\
3\end{array}$ & $\begin{array}{r}207 \\
173 \\
14 \\
20 \\
3\end{array}$ & $\begin{array}{r}213 \\
177 \\
15 \\
20 \\
3\end{array}$ \\
\hline $\begin{array}{l}\text { TERCERO } \\
\text { Promoción } \\
\text { Repeticion } \\
\text { Deserción } \\
\text { Promocion } \\
\text { sin mejora }\end{array}$ & $\begin{array}{r}110 \\
91 \\
7 \\
12 \\
11\end{array}$ & $\begin{array}{r}119 \\
101 \\
8 \\
10 \\
11\end{array}$ & $\begin{array}{r}131 \\
110 \\
9 \\
12 \\
9\end{array}$ & $\begin{array}{r}137 \\
113 \\
8 \\
16 \\
3\end{array}$ & $\begin{array}{r}137 \\
114 \\
8 \\
15 \\
1\end{array}$ & $\begin{array}{r}141 \\
118 \\
8 \\
15 \\
4\end{array}$ & $\begin{array}{r}140 \\
117 \\
8 \\
15 \\
0\end{array}$ & $\begin{array}{r}141 \\
118 \\
8 \\
15 \\
0\end{array}$ & $\begin{array}{r}141 \\
118 \\
8 \\
15 \\
0\end{array}$ & $\begin{array}{r}143 \\
119 \\
9 \\
15 \\
0\end{array}$ & $\begin{array}{r}149 \\
124 \\
9 \\
16 \\
1\end{array}$ & $\begin{array}{r}154 \\
131 \\
9 \\
15 \\
2\end{array}$ & $\begin{array}{r}164 \\
142 \\
8 \\
14 \\
3\end{array}$ & $\begin{array}{r}166 \\
144 \\
8 \\
14 \\
1\end{array}$ & $\begin{array}{r}169 \\
146 \\
8 \\
15 \\
2\end{array}$ & $\begin{array}{r}173 \\
150 \\
8 \\
15 \\
3\end{array}$ & $\begin{array}{r}178 \\
154 \\
9 \\
15 \\
3\end{array}$ & $\begin{array}{r}183 \\
159 \\
9 \\
15 \\
4\end{array}$ \\
\hline $\begin{array}{l}\text { CUARTO } \\
\text { Promoción } \\
\text { Repetición } \\
\text { Deserción } \\
\text { Promoción } \\
\text { sin mejora }\end{array}$ & $\begin{array}{r}85 \\
70 \\
5 \\
10 \\
1\end{array}$ & $\begin{array}{r}95 \\
81 \\
5 \\
9 \\
9\end{array}$ & $\begin{array}{r}106 \\
-\quad 90 \\
5 \\
11 \\
9\end{array}$ & $\begin{array}{r}115 \\
94 \\
5 \\
16 \\
4\end{array}$ & $\begin{array}{r}118 \\
98 \\
5 \\
15 \\
0\end{array}$ & $\begin{array}{r}119 \\
99 \\
5 \\
15 \\
0\end{array}$ & $\begin{array}{r}122 \\
101 \\
5 \\
16 \\
0\end{array}$ & $\begin{array}{r}123 \\
102 \\
5 \\
16 \\
0\end{array}$ & $\begin{array}{r}123 \\
102 \\
5 \\
16 \\
0\end{array}$ & $\begin{array}{r}124 \\
103 \\
5 \\
16 \\
1 \\
1\end{array}$ & $\begin{array}{r}128 \\
108 \\
5 \\
16 \\
1\end{array}$ & $\begin{array}{r}172 \\
114 \\
43 \\
15 \\
2\end{array}$ & $\begin{array}{r}145 \\
125 \\
5 \\
15 \\
2\end{array}$ & $\begin{array}{r}148 \\
127 \\
5 \\
15 \\
1\end{array}$ & $\begin{array}{r}150 \\
129 \\
6 \\
16 \\
1\end{array}$ & $\begin{array}{r}153 \\
132 \\
6 \\
16 \\
1\end{array}$ & $\begin{array}{r}157 \\
135 \\
6 \\
17 \\
3\end{array}$ & $\begin{array}{r}161 \\
139 \\
6 \\
17 \\
3\end{array}$ \\
\hline $\begin{array}{l}\text { QUINTO } \\
\text { Promoción } \\
\text { Pepetición } \\
\text { Deserción } \\
\text { Promoción } \\
\text { sin mejora }\end{array}$ & $\begin{array}{r}72 \\
60 \\
3 \\
9 \\
0\end{array}$ & $\begin{array}{r}75 \\
65 \\
3 \\
7 \\
5\end{array}$ & $\begin{array}{r}84 \\
73 \\
3 \\
8 \\
10\end{array}$ & $\begin{array}{r}93 \\
79 \\
3 \\
11 \\
6\end{array}$ & $\begin{array}{r}101 \\
89 \\
3 \\
9 \\
10\end{array}$ & $\begin{array}{r}102 \\
89 \\
3 \\
10 \\
5\end{array}$ & $\begin{array}{r}104 \\
91 \\
3 \\
10 \\
3\end{array}$ & $\begin{array}{r}105 \\
92 \\
3 \\
10 \\
3\end{array}$ & $\begin{array}{r}105 \\
92 \\
3 \\
10 \\
1\end{array}$ & $\begin{array}{r}105 \\
92 \\
3 \\
10 \\
1\end{array}$ & $\begin{array}{r}110 \\
97 \\
3 \\
10 \\
1\end{array}$ & $\begin{array}{r}115 \\
102 \\
3 \\
10 \\
0\end{array}$ & $\begin{array}{r}126 \\
113 \\
3 \\
9 \\
1\end{array}$ & $\begin{array}{r}129 \\
116 \\
3 \\
10 \\
2\end{array}$ & $\begin{array}{r}131 \\
118 \\
3 \\
10 \\
1\end{array}$ & $\begin{array}{r}133 \\
120 \\
3 \\
10 \\
2\end{array}$ & $\begin{array}{r}135 \\
122 \\
3 \\
11 \\
1\end{array}$ & $\begin{array}{r}139 \\
126 \\
3 \\
11 \\
3\end{array}$ \\
\hline $\begin{array}{l}\text { SEXTO } \\
\text { Promoción } \\
\text { Repetición } \\
\text { Deserción }\end{array}$ & $\begin{array}{r}62 \\
50 \\
2 \\
10\end{array}$ & $\begin{array}{r}62 \\
53 \\
2 \\
7\end{array}$ & $\begin{array}{r}65 \\
56 \\
2 \\
7\end{array}$ & $\begin{array}{r}75 \\
63 \\
2 \\
10\end{array}$ & $\begin{array}{r}81 \\
70 \\
2 \\
9\end{array}$ & $\begin{array}{r}86 \\
75 \\
2 \\
9\end{array}$ & $\begin{array}{r}90 \\
78 \\
2 \\
10\end{array}$ & $\begin{array}{r}91 \\
79 \\
2 \\
10\end{array}$ & $\begin{array}{r}93 \\
81 \\
2 \\
10\end{array}$ & $\begin{array}{r}93 \\
81 \\
2 \\
10\end{array}$ & $\begin{array}{r}98 \\
86 \\
2 \\
10\end{array}$ & $\begin{array}{r}104 \\
92 \\
2 \\
10\end{array}$ & $\begin{array}{r}114 \\
102 \\
2 \\
10\end{array}$ & $\begin{array}{r}116 \\
104 \\
2 \\
10\end{array}$ & $\begin{array}{r}119 \\
106 \\
2 \\
11\end{array}$ & $\begin{array}{r}120 \\
107 \\
2 \\
11\end{array}$ & $\begin{array}{r}123 \\
110 \\
2 \\
11\end{array}$ & $\begin{array}{r}125 \\
112 \\
2 \\
11\end{array}$ \\
\hline $\begin{array}{l}\text { Total de } \\
\text { ahos de } \\
\text { instrucción }\end{array}$ & 700 & 732 & 783 & 833 & 837 & 854 & 864 & 870 & 875 & 884 & 910 & 977 & 986 & 1006 & 1029 & 1049 & 1078 & 1104 \\
\hline $\begin{array}{l}\text { Promocion } \\
60 . \text { grado, \% } \\
\text { total anos } \\
\text { con }\end{array}$ & 7 & 7 & 7 & 8 & 8 & 9 & 9 & 9 & 9 & 9 & 9 & 9 & 10 & 10 & 10 & 10 & 10 & 10 \\
\hline $\begin{array}{l}\text { eficiencia } \\
\text { Porcentaje } \\
\text { de cohorte } \\
\text { que pasan } \\
\text { promocion a } \\
60 . \text { grado al } \\
\text { cabo de } \\
6 \text { anos }\end{array}$ & 1983 & 1984 & 1985 & 1986 & 1987 & 1988 & 1989 & 1990 & 1991 & 1992 & 1993 & 1994 & 1995 & 1996 & 1997 & 1998 & 1999 & 2000 \\
\hline
\end{tabular}

